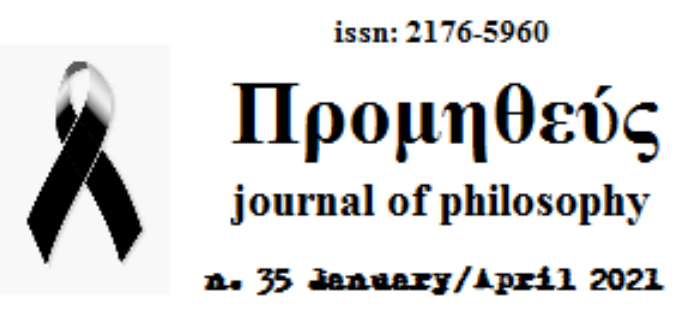

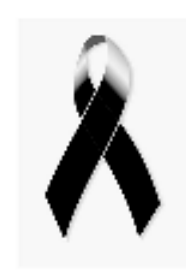

\section{APRESENTAÇÃO DO ARTIGO "EXPLICANDO A CONSCIÊNCIA" DE DAVID ROSENTHAL}

Tárik de Athayde Prata ${ }^{1}$

David Rosenthal é uma figura de grande destaque nos debates contemporâneos a respeito da consciência. O texto aqui traduzido expõe a sua teoria da consciência como característica de estados mentais, a influente "teoria dos pensamentos de ordem superior", ou "teoria HOT",", previamente exposta nos conhecidos artigos Two Concepts of Consciousness (1986) e $A$ Theory of Consciousness (1997) ${ }^{3}$. Mas o próprio Rosenthal considera a exposição da sua teoria em Explaining Consciousness (2002) mais clara e completa, e por isso ele nos pediu que preparássemos a presente tradução.

Entretanto, explicar a consciência não é uma tarefa nada fácil, pois já antes de qualquer tentativa, a dificuldade se mostra, na medida em que nunca é óbvio o que alguém quer dizer quando emprega a palavra "consciência". Como esclarece o próprio Rosenthal: "Parte da dificuldade se deve ao nosso uso do termo 'consciente' e seus cognatos para dar conta de diversos fenômenos distintos, cujas conexões entre si não são sempre claras. E isso nos leva, muitas vezes, a misturar estes diferentes fenômenos." (Rosenthal, 2002, p. 406). ${ }^{4}$

Ao longo da história, a polissemia em torno das palavras "consciência" e "consciente", sempre esteve presente. O substantivo "consciência" vem do latim "conscientia", que traduz o termo grego "syneidesis", originado da palavra "synoida" que significava, a princípio, um

\footnotetext{
${ }^{1}$ Graduado em Psicologia e Mestre em Filosofia Contemporânea pela Universidade Federal do Ceará (UFC). Doutor em Filosofia pela Ruprecht-Karl Universität Heidelberg (Alemanha). Professor Associado do Departamento de Filosofia da Universidade Federal de Pernambuco (UFPE).

${ }^{2}$ HOT é a sigla para "Higher-Order Thoughts".

${ }^{3}$ A edição original desse texto é de 1990, mas ele é mais conhecido por essa edição de 1997.

${ }^{4} \mathrm{Na}$ segunda nota de rodapé do artigo aqui traduzido, Rosenthal referencia a seguinte passagem das Investigações lógicas de Edmund Husserl, para evidenciar a polissemia do termo "consciência": "Que nem todos os equívocos do termo em questão estejam esgotados é coisa que mal precisa ser dita. Por exemplo, recordo maneiras de falar, correntes no uso extra-científico da língua, como 'entrar na consciência' ou 'vir à consciência', 'alta' ou 'reduzida consciência de si próprio' [reduzida auto-estima - T.A.P.], o 'despertar da consciência de si' (esta última expressão é também usada na Psicologia, mas com um sentido completamente diferente da vida corrente), e ainda outras semelhantes.” (Husserl, 1984, p. 356; Husserl, 2012, p. 295).
} 
saber compartilhado, como o saber de uma testemunha, de um confidente ou de um cúmplice, mas ainda na antiguidade se desenvolveu o significado de um saber consigo mesmo, expresso com ou sem o pronome reflexivo, e se desenvolveu também um significado moral (cf. Marietta Jr., 1970, p. 177).

É interessante notar que, até hoje, esses três domínios de sentido estão presentes nas discussões contemporâneas. Güven Güzeldere (1997, p. 8) coloca que as oito definições de "consciência" (consciousness) que encontramos no Oxford English Dictionary se dividem em dois grupos: (1) as que dizem respeito ao aspecto social (como quando se fala de "consciência de classe" ou de "consciência ecológica"); e (2) as que dizem respeito ao aspecto psicológico (tema que nos interessa aqui). Mas é obvio que ele também reconhece o uso (3) moral da palavra "consciência" (cf. Ibid., p. 49), uso que é tão importante que algumas línguas reservam uma palavra específica para ele (como "conscience", em inglês, ou "Gewissen" em alemão).

Em uma longa série de trabalhos (cf., por exemplo, Rosenthal, 1986; 1997; 2002; 2008a; 2008b; 2017) David Rosenthal procurou explicar a consciência em um sentido bastante específico: o sentido referente a uma certa característica de estados mentais, fenômeno que ele chama de "consciência de estado" (state consciousness). ${ }^{5} \mathrm{Na}$ presente introdução à tradução de seu artigo Explicando a consciência (2002), irei expor o que me parecem ser as linhas gerais de sua teoria (seção 1), que concebe a noção de um estado mental consciente em termos do "princípio da transitividade" (seção 2), seus argumentos contra a concepção perceptiva da consciência (seção 3), e a favor da concepção baseada em pensamentos (seção 4), bem como sua argumentação a favor da diferença entre os níveis psicológicos (seção 5), e dois dos principais argumentos que ele oferece para sustentar sua teoria dos pensamentos de ordem superior: o argumento da introspecção (seção 6) e o argumento do relato e da expressão de estados mentais (seção 7).

\section{Linhas fundamentais da teoria}

Assumindo que, enquanto executa conscientemente uma tarefa no trabalho, Maria está ciente do encontro que tem à noite, embora não esteja pensando sobre isso, é bastante razoável pensar essa ciência (awareness) em termos de algum tipo de representação desse

\footnotetext{
${ }^{5}$ A respeito das distinções propostas por Rosenthal entre (1) consciência de criatura e consciência de estado; (2) consciência introspectiva e consciência não introspectiva; e (3) consciência intransitiva e consciência transitiva, cf. Rosenthal, (1997), p. 729-30, p. 736-7; Rosenthal, (2017), p. 144-45, p.158-59; bem como Kriegel, (2009), pp. 23-32; Prata, (2017a), pp. 433-37; Prata, (2017b), pp. 135-40.
} 
estado de coisas possível (o estado de coisas de se encontrar com dada pessoa, em dado horário e local). Para fins de simplificação, deixemos de lado a representação complexa desse estado de coisas, e pensemos na crença de Maria de que Pedro, com quem ela terá o encontro, é um homem atraente. ${ }^{6}$ Partindo da já bem estabelecida distinção entre o (1) modo psicológico de um estado mental e o seu (2) conteúdo representacional (cf. Husserl, 1984, p. 426; Husserl, 2012, p. 367; Searle, 1983, p. 5-7; Searle, 1995, p. 8-10), podemos representar a ciência de Maria sobre seu compromisso através da seguinte figura, onde o "S" maiúsculo substitui o estado mental (dotado de um certo modo psicológico), o "p" minúsculo substitui o estado de coisas a respeito do qual o estado mental é, o " $p$ ” minúsculo em itálico substitui a representação mental proposicional desse estado de coisas, e a seta pontilhada substitui a relação intencional inconsciente entre e estado mental (S) e o estado de coisas (p):

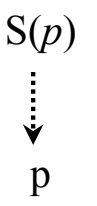

Está, assim, representada a crença inconsciente de Maria de que Pedro é um homem atraente. Adicionando um índice numérico para indicar a ordem psicológica de cada estado mental, representando o pensamento metapsicológico com um "P" maiúsculo, e representando a propriedade de um estado mental de ser consciente através de um asterisco $\left(^{*}\right)$, podemos representar a situação na qual a ciência de Maria sobre a atratividade de Pedro se torna consciente através da seguinte figura:

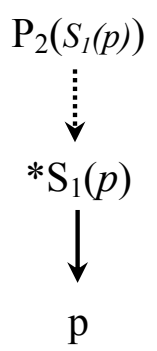

Nesta figura, a relação intencional entre o estado mental de primeira ordem e o estado de coisas externo é representada por uma seta continua, pois, uma vez que o estado mental de

\footnotetext{
${ }^{6}$ Em um caso como esse, o conteúdo proposicional " $p$ " representaria um estado de coisas simples, que poderia ser, também, apresentado na notação através da expressão " $F(a)$ ", indicando que um certo indivíduo "a" ( $p$. ex., Pedro) exemplifica uma certa propriedade "F" (p. ex., a propriedade de ser atraente).
} 
primeira ordem exemplifica consciência $(*)$, essa relação intencional (transitiva) se tornou consciente. Mas essa segunda figura ainda não corresponde adequadamente à teoria de Rosenthal, pois, segundo ele, o pensamento de segunda ordem não é, simplesmente, acerca do estado mental de primeira ordem, mas ele é, sim, a respeito do fato de que a pessoa em questão se encontra naquele estado mental (cf. Rosenthal, 1986, p. 344; 1997, p. 741; 2017, p. 166). Isso significa que, no conteúdo do pensamento metapsicológico tem de estar incluído algum tipo de representação da pessoa, uma representação do eu em questão. Acrescentando tal representação, na forma do símbolo " $\varepsilon$ ", e o símbolo “+” para significar a relação de se encontrar em um estado mental, podemos representar a situação do estado mental consciente, mais acuradamente, através da seguinte figura:

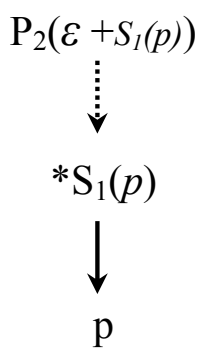

Fica assim delineada uma teoria na qual a consciência $\left(^{*}\right)$ como propriedade de um estado mental (S) é concebida em termos de uma ciência inconsciente (seta pontilhada) que a pessoa $(\varepsilon)$ possui sobre esse estado mental $(\mathrm{S})$, de modo que essa pessoa se torna conscientemente ciente ${ }^{7}$ (seta contínua) de um dado estado de coisas (p) no mundo. Nesse sentido, trata-se de uma teoria na qual a consciência $\left(^{*}\right)$ como propriedade de um estado mental (S) consiste em um determinado tipo de autoconsciência, pois o estado mental (S) só adquire consciência $\left(^{*}\right)$ quando o sujeito está consciente de si mesmo $(\varepsilon)$ enquanto se encontra nesse estado mental.

Rosenthal considera que a principal vantagem dessa teoria é que ela viabiliza uma explanação informativa a respeito da consciência como característica de estados mentais (cf. Rosenthal, 1986, p. 339), mas deixarei esse tema de lado, porque ele exige uma discussão teórica acerca das condições necessárias para se obter uma explanação adequada de um

\footnotetext{
${ }^{7}$ Embora possa parecer a alguém que falar de uma "ciência consciente" é uma redundância, é importante notar que, como evidencia Rocco Gennaro: "É claro que 'ciente' [aware] e 'consciente' [conscious] não são meramente sinônimos (...). Não é contraditório falar de ser 'inconscientemente ciente' de algo. De modo similar, a expressão 'conscientemente ciente' não é redundante. Ciência não necessariamente carrega conotações de consciência." (Gennaro, 1996, p. 5).
} 
fenômeno, e eu pretendo me ater aqui aos argumentos relativos à constituição dos próprios fenômenos mentais (a respeito da argumentação de Rosenthal referente à explanação da consciência, cf. Rosenthal, 1986, p. 330; 1997, p. 735; 2017, p. 154-55). A formulação específica da teoria de Rosenthal é a de que os estados mentais que nos tornam cientes de alguns de nossos outros estados mentais são pensamentos, em lugar de percepções (cf. Armstrong, 1968, p. 94; 1997, p. 724), de modo que se torna necessário examinar as objeções dele contra a concepção perceptiva da consciência (cf. a seção 3 a seguir).

A partir da alegação de que é a ideia de consciência como propriedade intrínseca aos fenômenos mentais que inviabiliza uma explanação informativa, Rosenthal defende que a consciência tem que ser pensada como uma propriedade extrínseca, isto é, uma propriedade relacional (cf. Rosenthal, 1997, p. 736; 2017, p. 156), de modo que um estado mental se torna consciente quando ele se encontra em uma relação apropriada com outro estado mental (segundo ele um pensamento assertórico), o que justificaria a distinção entre níveis psicológicos (primeira ordem, segunda ordem, etc.).

\section{O princípio da transitividade}

Se Maria está (inconscientemente) ciente de que Pedro é um homem atraente, isso significa que ela se encontra em um estado mental cujo conteúdo representacional diz respeito a esse propriedade de Pedro (cf. Rosenthal, 1997, p. 737; 2017, p. 159). E, de acordo com a teoria, esse estado mental deixa de ser inconsciente quando Maria se torna ciente desse estado, ou melhor, se torna ciente do fato de que ela se encontra nesse estado, o que significa que ela se encontra em um estado metapsicológico que diz respeito a este ultimo fato.

Nesse sentido, a ciência que Maria (eventualmente) possui de sua condição de se encontrar em um dado estado mental é concebida de maneira análoga à ciência que Maria (eventualmente) possui de um objeto externo, pois, nos dois casos, trata-se de uma relação propiciada por um certo estado mental, cujo conteúdo diz respeito a determinado tema, seja um objeto externo, seja um estado mental.

Rosenthal chama essa maneira de explicar a consciência como uma propriedade de estados mentais (ou seja, uma maneira de formular em que essa consciência consiste) de princípio da transitividade, de acordo com o qual: "um estado é consciente se alguém [one] é consciente do estado de maneira adequada.” (Rosenthal, 2008a, p. 240). E esse princípio 
parece bastante intuitivo, uma vez que parece evidente que um estado mental do qual seu portador não está consciente não poderia ser um estado consciente.

A relação transitiva, isto é, intencional entre um dado estado mental e um dado estado de coisas conecta psicologicamente o portador desse estado mental a esse estado de coisas, e o pensamento de segunda ordem, por sua vez, conecta o portador (que é portador tanto do pensamento de segunda ordem quanto do estado mental de primeira ordem) a esse estado mental, tornando-o um estado consciente, ao tornar o portador consciente desse estado.

Uma conhecida objeção ao princípio da transitividade (princípio que constitui o próprio conceito de um estado mental consciente na teoria de Rosenthal), foi formulada por Fred Dretske (1993, p. 278-79; cf. também Byrne, 1997, p. 113-14), que apela para situações nas quais não conseguimos notar pequenas diferenças entre estados de coisas dos quais estamos cientes, para abalar a convicção de que é a nossa ciência de estados mentais que torna estes últimos conscientes. Suponhamos que Maria encontra Pedro à noite, após o trabalho, e que ela o encontra novamente dias depois, em outras circunstâncias. Suponhamos que na primeira circunstância, a do encontro noturno, ele estava bem barbeado, com a pele em perfeito estado, mas no segundo encontro ele tem um pequeno arranhão junto à orelha esquerda, fruto de um descuido ao barbear-se novamente. Suponhamos, ainda, que, nas duas circunstâncias, Maria olhou longamente para o rosto de Pedro, de modo que seu olhar se deteve, em algumas oportunidades, sobre a pele do rosto próxima à orelha esquerda, mas que Maria não nota o arranhão.

A partir de uma situação como essa, Dretske argumenta que podem haver diferenças nas características da experiência consciente de uma pessoa (em duas circunstâncias) sendo, porém, diferenças das quais a pessoa não está consciente, o que, segundo ele, mostra que "não pode ser a ciência [awareness] de uma pessoa sobre um estado mental que faz consciente esse estado mental." (Dretske, 1993, p. 278).

Todavia, este não é um argumento convincente, uma vez que do fato de que um pensamento de segunda ordem torna um estado mental de primeira ordem consciente não se segue que tenhamos que ter um conhecimento exaustivo do estado de coisas externo que é representado por esse estado mental. O estado de coisas é complexo e o conteúdo representacional do estado de primeira ordem pode falhar em representar algum detalhe. Diante disso, concluo que o princípio da transitividade de Rosenthal preserva seu apelo intuitivo. ${ }^{8}$

\footnotetext{
${ }^{8}$ Para uma refutação mais detalhada do argumento de Dretske, cf. Byrne, (1997), pp. 113-14.
} 


\section{Contra a concepção perceptiva da consciência}

Vimos que a teoria de Rosenthal concebe a ciência [awareness] que possuímos sobre alguns dos nossos estados mentais como análoga à ciência que possuímos de certos objetos externos, pois, nos dois casos, o conteúdo representacional de um estado mental nos conecta psicologicamente com algo para além desse estado. Se é assim, parece intuitivo pensar que nossa consciência de (alguns de) nossos próprios estados mentais é produzida por algum mecanismo perceptivo, afinal é o nosso aparato perceptivo (visão, audição, olfato, etc.) que nos torna diretamente cientes de objetos e estados de coisas no ambiente ao nosso redor. Certamente foram considerações como essas que estiveram na raiz do antiquíssimo modelo de um sentido interno (conceito já encontrado em grandes filósofos do passado, como Aristóteles, Locke, Kant, entre muitos outros).

Mas a tese de Rosenthal é que nossa ciência de nossos próprios estados mentais não é um tipo especial de sensação, pois essa ciência não é caracterizada pelo colorido vivencial (formado por aspectos qualitativos) que caracteriza as sensações e percepções. Por isso Rosenthal recusa a ideia de um sentido interno, em favor da tese de que são pensamentos, isto é, entidades psicológicas mais abstratas (menos providas de caracteres sensíveis) que nos tornam cientes de nossos estados mentais.

Entendo que a argumentação de Rosenthal (1997, p. 740; 2017, p. 164; 2008a, p. 24142) contra a perspectiva perceptiva pode ser reconstituída da seguinte maneira:

(1) Estados mentais conscientes são estados dos quais estamos cientes de nos encontrar (princípio da transitividade);

(2) Estados intencionais nos tornam cientes de (i) objetos, de (ii) estados de coisas e de (iii) estados mentais;

(3) Existem estados intencionais sensoriais e estados intencionais mais abstratos (pensamentos);

(4) Estados intencionais sensoriais possuem um aspecto qualitativo peculiar;

(5) Não vivenciamos um aspecto qualitativo peculiar quando nos tornamos cientes de (alguns de) nossos estados mentais;

(C) Nossa ciência de nossos próprios estados mentais não é produzida por estados intencionais sensoriais. 
Além disso, Rosenthal argumenta que enquanto as diferentes modalidades sensoriais (visão, audição, olfato, etc.) são especializadas em certos tipos de estímulos (luminosos, sonoros, gasosos, etc.), os estados mentais que, por hipótese, são os objetos do sentido interno, não exemplificam propriedades similares pois, na verdade, eles tem pouco em comum entre si - pensemos na diferença entre uma sensação de cor e um cálculo matemático, por exemplo -, e mesmo se nos restringíssemos a estados mentais sensoriais teríamos que admitir que eles tem qualidades sensoriais muito distintas entre si - pensemos na diferença entre uma sensação de cor e uma sensação auditiva, por exemplo (cf. Rosenthal, 1997, p. 739; 2017, p. 163). Desse modo, a visão da consciência de estados mentais como algum tipo de sensação ou percepção não se mostra plausível.

\section{A favor da concepção dos pensamentos}

Do mesmo modo como posso me tornar ciente de certo objeto em minhas imediações através de uma sensação ou percepção dele, posso me tornar ciente dele (e de outras coisas) através de pensamentos. Se vi há pouco um certo alimento próximo a mim, posso continuar ciente de sua presença, quando não o vejo, através do pensamento de que esse alimento se encontra próximo. Além disso, no caso de coisas que não posso perceber diretamente, inclusive porque elas não tem uma existência puramente física ${ }^{9}$ (coisas como a taxa de desemprego ou o sistema de governo de um país), os pensamentos se mostram como o tipo apropriado de estado mental para que possamos ter ciência dessas coisas. É interessante notar que, também no caso de certas realidades físicas, que sejam muito pequenas (p. ex. a estrutura molecular de um objeto) ou muito vastas (p. ex. o regime de chuvas de uma dada região) para serem observadas diretamente ${ }^{10}$, pensamentos são o meio mais apropriado para se obter ciência a respeito delas.

No caso de nossos próprios estados mentais, Rosenthal defende que pensamentos são, também, o tipo de estado intencional mais apropriado para que nos tornemos cientes deles. Ele defende isso, em parte, devido às dificuldades da noção de um sentido interno (cf. a seção anterior), mas também por outros motivos. O pensamento (diferente das sensações) não se

\footnotetext{
${ }^{9}$ Ao dizer que elas não possuem uma existência puramente física, estou sugerindo que certas entidades até possuem aspectos físicos, embora não se limitem a eles.

10 Obviamente, estou entendendo "observação direta" em termo de uma percepção imediata em um dado instante, e não como um conhecimento construído a partir de um grande número de percepções ao longo de certo período.
} 
restringe a tipos específicos de objetos, e sua relação com seus objetos é, pelo menos, tão imediata quanto a relação das sensações e percepções com seus objetos.

Rosenthal reconhece que a palavra "pensamento" pode ser usada de maneira altamente genérica, designando qualquer tipo de estado intencional (como crenças, expectativas, antecipações, desejos, imaginações, suspeitas, etc.) independentemente de seu modo psicológico. Mas na formulação de sua teoria da consciência como característica de estados mentais, ele emprega essa palavra em um sentido específico, a saber, o sentido de um pensamento assertórico, um pensamento que (através de seu conteúdo proposicional) afirma ou nega algo determinado a respeito de um estado de coisas no mundo. E ele defende que não é qualquer modo psicológico (como o de duvidar ou de imaginar) que torna um sujeito consciente de algo, mas apenas o modo psicológico assertivo, pois esse modo psicológico é o que nos conecta com aquilo que é apreendido pelo estado intencional. Como explica Rosenthal:

Não é a dúvida, imaginação, esperança ou desejo que nos torna conscientes do objeto. Se eu duvido que o objeto é vermelho, ou desejo, ou suspeito que assim seja, devo ao menos pensar assertoricamente que o objeto está lá. Igualmente com o duvidar, esperar ou antecipar que meu estado mental tenha alguma propriedade; devo ao menos ter o pensamento assertórico de que estou naquele estado mental. Do mesmo modo, não devemos supor que tais atitudes não-assertóricas farão um indivíduo consciente de se encontrar neste estado mental, a não ser que ter a atitude também envolva um pensamento afirmativo de que o indivíduo se encontra naquele estado. $\mathrm{O}$ mesmo vale para estados tais como raiva e prazer, quando estes são concebidos proposicionalmente. (Rosenthal, 1997, p. 742; 2017, p. 168).

A ideia de Rosenthal parece ser que quando um estado intencional (S), dotado de conteúdo representacional proposicional $(p)$ possui um modo psicológico assertivo, esse estado intencional coloca seu portador (o sujeito em questão) em contato com o estado de coisas (p) representado no conteúdo, ou seja, conecta-o psicologicamente com esse estado de coisas. Quando esse estado de coisas é inconscientemente representado (seta pontilhada) pelo estado intencional (S), o portador está inconscientemente ciente do estado de coisas externo. Mas quando o portador tem um pensamento de segunda ordem (P) que representa (inconscientemente) o fato de que o portador se encontra naquele estado intencional (S), o portador se torna ciente desse estado, o que torna esse estado intencional um estado mental consciente $(* S)$. Quando o portador, através do pensamento de segunda ordem (que tem o 
modo psicológico assertórico) se torna ciente da presença do estado intencional (S) em seu psiquismo, esse estado se torna um estado mental intencional consciente.

\section{A favor da diferença entre os níveis psicológicos}

Se um estado mental consciente é um estado do qual estamos cientes de nos encontrar (seção 2), e se nos tornamos cientes de nos encontrar nele através de pensamentos assertóricos (seção 4), e não de percepções internas (seção 3), que motivos temos para alegar que o estado mental consciente $\left({ }^{*} \mathrm{~S}\right)$ e o pensamento de segunda ordem $\left(\mathrm{P}_{2}\right)$ são fenômenos diferentes? Durante milênios, a ideia de um fenômeno mental inconsciente não teve defensores (cf. Brentano 1924, p. 144; 1995, p. 103) ${ }^{11}$, e foi somente na segunda metade do século XIX que essa ideia ganhou força (cf. Rosenthal, 2008a, p. 240), e uma maneira de defender a tradicional visão cartesiana, segundo a qual a consciência é essencial aos fenômenos mentais (cf. Descartes, 1979, p. 169 [AT, VII, p. 160; AT, IX, p. 124] ${ }^{12}$ ), é considerar que aquilo que nos torna cientes de um fenômeno mental já está embutido nesse fenômeno mental, ele mesmo.

Se aceitarmos a tese cartesiana de que todo fenômeno propriamente mental (e não meramente disposicional) ${ }^{13}$ é um fenômeno consciente, e se defendermos que a diferença entre o fenômeno mental consciente e o (outro) que o torna assim, segue-se um regresso ao infinito, pois "nenhum estado mental poderia ser consciente sem ser acompanhado por um pensamento de ordem superior. Mas esse pensamento teria que ser ele mesmo consciente, e assim um pensamento de ordem ainda superior seria necessário" (Rosenthal, 1986, p. 340; cf. Byrne, 1997, p. 108; Gennaro, 2004, p. 5), de modo que a série de pensamentos, um a respeito do outro, jamais teria fim. A maneira mais viável de evitar esse regresso (que é (a) absurdo pois não poderíamos ter um numero infinito de estados mentais correspondentes a cada estado mental de primeira ordem - e também (b) algo que nós não vivenciamos - e, na verdade, não poderíamos vivenciar ${ }^{14}$ ) é alegar que o pensamento que nos torna cientes de um estado mental

\footnotetext{
11 “Até muito recentemente na história da ciência e da filosofia, a vida mental era considerada inteiramente, ou principalmente, consciente em sua natureza" (Bargh \& Morsella, 2008, p. 73).

${ }^{12}$ Entre colchetes estão indicadas as referências ao volume VII (latim) e ao volume IX (francês) da edição das obras de Descartes organizada por Charles Adam e Paul Tannery (AT).

${ }^{13}$ Sobre a concepção disposicional dos fenômenos mentais inconscientes, cf. Rosenthal, 1986, p. 329, p. 342; Rosenthal, (1997), p. 732; Rosenthal, (2017), p. 149; bem como Prata, (2018a).

${ }^{14}$ É simplesmente absurdo supor que poderíamos ter, literalmente, consciência de um número infinito de estado mentais, em um único instante no tempo.
} 
não é diferente dele, mas, na verdade, faz parte dele. Em outras palavras, todo estado mental consciente seria, em parte, a respeito de si mesmo (cf. Rosenthal, 1986, p. 344).

Contra essa perspectiva, que foi efetivamente defendida por Brentano (1924) e outros (cf., por exemplo, Smith, 1986, p. 150), Rosenthal argumenta que qualquer coisa que possa ser interpretada como um indício a favor dessa visão (da consciência como intrínseca aos estados mentais) também pode ser interpretada como um indício a favor da visão oposta (da consciência de um estado mental como dependente de um outro estado mental separado), o que, provavelmente, no meu modo de entender, decorre do fato de que não há nenhum modo de descrever um estado mental como parte de um outro que não seja arbitrário (a esse respeito, cf. Kriegel, 2005, p. 31-32).

Mas especialmente devastador para a noção de consciência como intrínseca aos estados mentais é o fato de que essa noção também leva a um regresso ao infinito, ainda que de um outro tipo. O ponto é que se é uma parte de um estado mental que torna esse estado consciente (tornando seu portador ciente dele), se essa parte for consciente, então ela também tem que ser representada no conteúdo do estado mental, o que exige uma representação dessa parte, representação esta que, se também for consciente, então também terá que ser representada, e assim sucessivamente (cf. Rosenthal, 1986, p. 345), de modo que o estado mental consciente terá uma infinita complexidade interna (cf. Brentano, 1924, p. 147-8; Brentano, 1995, p. 105), situação que Brentano pensava ter evitado com o recurso à autorepresentação dos estados conscientes.

Por outro lado, se a parte do estado mental que torna esse estado consciente for uma parte inconsciente desse estado mental, não parece haver uma razão substantiva para afirmar que um é parte do outro (além do simples desejo de aderir à visão cartesiana), o que torna a visão que distingue o estado mental consciente do pensamento de segunda ordem, no mínimo, uma opção perfeitamente legítima.

\section{O argumento da introspecção}

Se a consciência característica de um estado mental consiste em estarmos cientes de nos encontrarmos nele (seção 2), se essa ciência não consiste em uma percepção interna (seção 3), mas sim em um pensamento (seção 4) de ordem superior (seção 5), que é um pensamento inconsciente, já temos as linhas fundamentais da teoria de Rosenthal. Mas ainda precisamos examinar outros argumentos que ele traz em seu apoio (cf. as seção 6 e 7). 
Um argumento que desfruta de destaque nas reflexões dele é o de que a teoria de pensamentos de ordem superior explica a intuição de que um estado mental consciente é um possivel objeto de introspecção (cf. Rosenthal, 1986, p. 338). Se introspecionar um estado mental é ter um pensamento consciente sobre esse estado, e se, para ser consciente, o pensamento sobre o estado mental tem que ser, por sua vez, objeto de um outro pensamento, isso significa que a introspecção de um estado mental de primeira ordem exige a presença de um pensamento de terceira ordem (cf. Rosenthal, 1986, p. 337), que torna consciente o pensamento de segunda ordem que, por sua vez, torna consciente o estado mental de primeira ordem.

E considerando que o conteúdo do pensamento de segunda ordem é que a pessoa em questão $(\varepsilon)$ se encontra $(+)$ no estado mental de primeira ordem $\left(\mathrm{S}_{1}\right)$, isso significa que o pensamento de terceira $\left(\mathrm{P}_{3}\right)$ ordem torna consciente a representação do eu $(\varepsilon)$ da pessoa em questão. Além disso, como a representação do estado mental de primeira ordem $\left(\mathrm{S}_{1}\right)$ faz parte do conteúdo do pensamento de segunda ordem $\left(\mathrm{P}_{2}\right)$, uma vez que este pensamento de segunda ordem se torna consciente $(*)$, o estado mental de primeira ordem entra no domínio da atenção do sujeito psicológico $(\varepsilon)$ que é o portador de todos esses estados mentais $\left(\mathrm{S}_{1}, \mathrm{P}_{2}, \mathrm{P}_{3}\right)$.

A introspecção de um estado mental de primeira ordem pode ser representada através do seguinte esquema, no qual a linha pontilhada representa uma relação intencional inconsciente, a linha contínua representa uma relação intencional consciente, e a linha tracejada representa uma relação intencional que se encontra na periferia da atenção:

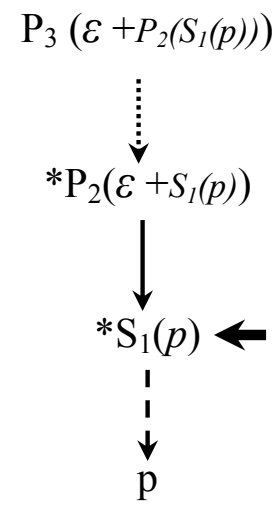

Nesse esquema, a seta horizontal indica o estado mental que se encontra no foco $d a$ atenção do sujeito, que é o portador de todos esses estados mentais (de primeira, segunda e terceira ordem). E a intuição de que um estado mental consciente é sempre um possível objeto de introspecção é explicada em termos do fato de que sempre se pode ter um pensamento de 
terceira ordem, que torne consciente o pensamento de segunda ordem, que nos torna conscientes do estado mental (de primeira ordem) no qual nos encontramos (cf. Rosenthal, 1997, p. 745-46; 2017, p. 175). Como escreve Rosenthal:

É uma característica de nossa experiência que, quando um estado mental é consciente, nós podemos prontamente vir a ter um pensamento consciente sobre esse estado mental. Na presente concepção, não vimos a ter um novo pensamento sobre esse estado mental, nós simplesmente vimos a nos tornar conscientes de um pensamento que nós já tínhamos, ainda que inconscientemente. Pensamentos de ordem superior são estados mentais dos quais podemos nos tornar cientes mais ou menos à vontade. A consciência de um estado mental equivale, portanto, a ele ser introspeccionável. (1986, p. 338).

Mas além, da alegação de que a teoria dos pensamentos de ordem superior explica a intuição de que todo estado mental consciente é introspeccionável, Rosenthal (1997, p. 746; 2017, p. 176), articula outro argumento a favor da teoria com base no conceito de introspecção. Para ele, a ideia de que a introspecção deve ser explicada em termos de um pensamento de ordem superior ${ }^{15}$ indica outra maneira de fundamentar a teoria, pois do mesmo modo como (intuitivamente) parece haver algo mais na consciência introspectiva de um estado mental do que na simples consciência não introspectiva desse mesmo estado (pois, de fato, é claramente diferente para nós (a) simplesmente vivenciar um estado mental e (b) examinar deliberadamente esse estado vivenciado), também parece haver algo mais na consciência não-introspectiva de um estado mental do que na total falta de consciência (afinal, há um modo como é vivenciar um estado mental consciente, enquanto que o estado mental inconsciente é como que um nada para nós). Desse modo, estados (simplesmente) conscientes são como que um meio termo entre os estados introspectivamente conscientes (que envolvem algo mais do que os estados simplesmente conscientes) e os estados inconscientes (que envolvem algo menos do que os estados conscientes). E se estados introspectivamente conscientes abarcam um pensamento consciente sobre eles, enquanto estados inconscientes não tem nenhum pensamento de ordem superior conectado a eles, devemos concluir que os estados (simplesmente) conscientes devem ser acompanhados por pensamentos (de segunda

15 É interessante notar que Jean-Paul Sartre caracterizava a introspecção, chamada por ele de consciência reflexiva, como consciência de "segundo grau" (cf. Sartre, 1966, p. 28; Sartre, 2010, p. 190). Para um exame da concepção sartriana da consciência, a partir do ponto de vista da filosofia da mente, cf. Prata, (2016a); Prata, (2016b); Prata, (2017c); Prata, (2018b); Prata, (2019a). 
ordem) inconscientes. ${ }^{16}$ A relação entre os três casos pode ser representada através do seguinte esquema:

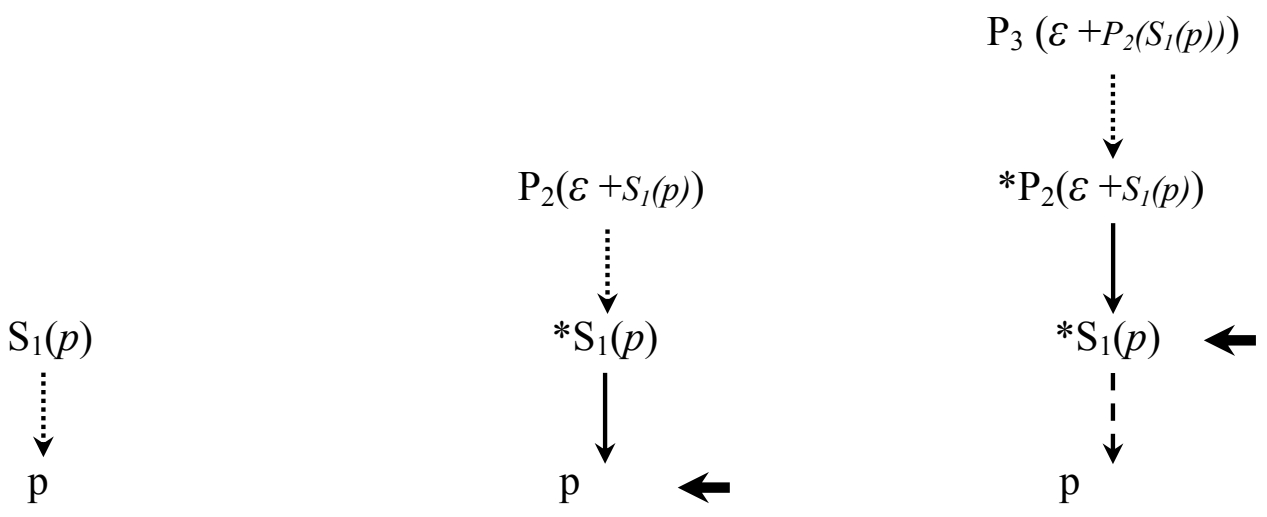

A seta horizontal que, na coluna do meio, aponta para o estado de coisas externo, na coluna da direita aponta para o estado mental de primeira ordem. Essa mudança na posição da seta horizontal representa no deslocamento da atenção do sujeito, atenção que se desloca do estado de coisas externo para o próprio estado mental no qual o sujeito se encontra. Mas além dessa argumentação baseada no conceito de introspecção, Rosenthal oferece um argumento baseado em nossas capacidades de reportar e de expressar os estados mentais nos quais nos encontramos.

\section{7. $O$ argumento do relato e da expressão ${ }^{17}$}

Rosenthal nos lembra que Brentano considerava que todo estado mental é, em parte, a respeito de si mesmo, porque não há diferença entre o estado mental de perceber ou de pensar algo e o estado mental de pensar que se percebe ou que se pensa esse algo, o que leva Brentano a concluir que um pensamento de segunda ordem é indistinguível do estado mental a respeito do qual ele é (cf. Rosenthal, 1997, p. 746; 2017, p. 177), o que vai ao encontro da visão dele da consciência como uma propriedade intrínseca dos estados mentais.

Contra Brentano, Rosenthal argumenta que estados mentais de primeira ordem e pensamentos de segunda ordem acerca deles não são indistinguíveis, pois embora ambos

\footnotetext{
${ }^{16}$ A alternativa de pensamentos de ordem superior meramente disposicionais é recusada por Rosenthal em diversas passagens (cf. Rosenthal, 1986, p. 338; Rosenthal, 1997, p. 742; Rosenthal, 2017, p. 169; Rosenthal, 2002, p. 410-11).

${ }^{17}$ Sobre esse argumento, cf. também (cf. Byrne, 1997, p. 108-9; Rosenthal, 1993, p. 204-5).
} 
tenham as mesmas condições de performance (nós pensaríamos ambos - (a) a crença de que Pedro é um homem atraente e (b) o pensamento de que eu penso que eu creio que Pedro é um homem atraente - nas mesmas circunstâncias), eles tem diferentes condições de verdade (pois pode ser verdadeiro que eu (a) pense conscientemente que Pedro é um homem atraente sem que seja verdade que eu (b) penso conscientemente que eu creio que Pedro é um homem atraente), e podem ter diferentes modos psicológicos (se o estado mental de primeira ordem não for um pensamento assertórico). Assumindo que reportar e expressar um estado mental são coisas diferentes (pois uma coisa é reportar um estado ao dizer "eu penso que Pedro é um homem atraente", e outra coisa é, simplesmente, expressa-lo, dizendo que "Pedro é um homem atraente"). Rosenthal enfatiza que esses dois atos tem diferentes condições de verdade (embora tenham as mesmas condições de performance) e podem ter diferentes forças ilocucionárias. ${ }^{18}$

Se nos restringirmos ao caso de seres com uma competência linguística similar à nossa, não é difícil perceber que um dado estado mental só pode ser consciente se seu portador for capaz de reporta-lo, pois não se pode reportar um estado mental do qual não se tem consciência. E em todo ato de fala sincero e significativo (ou seja, que não seja um disparate) é expresso um estado com o mesmo conteúdo e uma atitude mental análoga à força ilocucionária do ato de fala. Com base nessa caracterização do relato de um estado mental, Rosenthal assevera:

Quando relato que me encontro em um estado mental, portanto, meu ato de fala expressa meu HOT de que estou, eu mesmo, naquele estado mental específico. A habilidade de relatar um estado mental é, assim, a mesma que a habilidade de expressar aquele pensamento proposto, justamente, pela teoria HOT. Então um estado mental é consciente se, e somente se, for possível expressar um HOT adequado sobre aquele estado. (Rosenthal, 1997, p. 747; Rosenthal, 2017, p. 178).

Nessa argumentação a favor de sua teoria, Rosenthal já acentua a distinção entre o estado mental de primeira ordem e o pensamento assertórico de segunda ordem que torna o primeiro consciente (contra esse argumento, cf. Byrne, 1997, p. 109-10). Os argumentos expostos na presente (seção 7) e na seção anterior (seção 6), permitem perceber parte do apelo que por Rosenthal enxerga em sua teoria do pensamentos de ordem superior, enquanto uma explicação da consciência de estado.

\footnotetext{
${ }^{18}$ Sobre a noção de força ilocucionária, cf. Searle, (1969), p. 22; Searle, (1981), p. 34; bem como Prata, (2016c), pp. 264-66.
} 


\section{Referências bibliográficas}

Armstrong. D. A Materialist Theory of Mind. London: Routledge \& Kegan Paul, 1968.

Armstrong. D. "What is Consciousness?". In: Block, N. (Org.); Flanagan, O. (Org.); Güzeldere, G. (Org.). The Nature of Consciousness: Philosophical Debates. Cambridge (Massachusetts): MIT Press, pp. 721-728, 1997.

Bargh, J. A.; Morsella, E. "The Unconscious Mind". In: Perspectives on Psychological Science, Vol. 3, $\mathrm{N}^{\mathrm{o}}$ 1, pp. 73-79, 2008.

Brentano, F. Psychologie vom empirischen Standpunkt. 2a edição. Leipzig: Felix Meiner, 1924.

Brentano, F. Psychology from an empirical standpoint. London: Routledge \& Kegan Paul, 1995.

Byrne, A. "Some Like It Hot: Consciousness and Higher-Order Thoughts." In: Philosophical Studies, 86, pp. 103-29, 1997.

Dretske, F. “Conscious Experience”. In: Mind, Vol. 102, pp. 263-83, April 1993.

Gennaro, R. (Org.) Higher-Order Theories of consciousness: An anthology. Amsterdam, Philadelphia: John Benjamins Publishing, pp. 227-254, 2004.

Gennaro, R. Consciousness and Selfconsciousness: a Defense of the Higher Order Thought Theory of Consciousness. Amsterdam/Philadelphia: John Benjamins Publishing, 1996.

Güzeldere, G. "Introduction - Many Faces of Consciousness: A Field Guide". In: Block, N. (Org.); Flanagan, O. (Org.); Güzeldere, G. (Org.). The Nature of Consciousness: Philosophical Debates. Cambridge (Massachusetts): MIT Press, pp. 1-67, 1997.

Husserl, E. Logische Untersuchungen II: Untersuchungen zur Phanomenologie und Theorie der Erkenntnis. Den Haag: Martinus Nijhoff, 1984. (Husserliana XIX/Parte 2).

Husserl, E. Investigações Lógicas: Segundo volume, parte I: Investigações para a Fenomenologia e Teoria do Conhecimento. Trad. Pedro M. S. Alves. Rio de Janeiro: Forense Universitária, 2012.

Kriegel, U. "Naturalizing Subjective Character" In: Philosophy and Phenomenological Research, Vol. LXXI, N 1, pp. 23-57, July 2005.

Kriegel, U. Subjective Consciousness: A Self-representational Theory. Oxford: Oxford University Press, 2009.

Marietta Jr, D. E. “Conscience in Greek Stoicism”. In: Numen, Vol. 17, Fasc. 3, pp. 176-187, Dec., 1970. 
Prata, T. A. "Consciência e auto-relação na primeira filosofia de Sartre: em exame a partir de um debate contemporâneo a respeito da consciência", Ágora Filosófica, Ano 16, N², pp. 7692, 2016a.

Prata, T. A. "As perspectivas de Brentano e Sartre sobre a auto-referencialidade da consciência". Rapsódia, 10, pp. 42-62, 2016 b.

Prata, T. A. "John Searle: Atos de fala, intencionalidade e linguagem". In: Peruzzo Júnior L. (Org.); Bortolo, V. (Org.). Filosofia da Linguagem. Curitiba: PUCPRess, pp 247-292, 2016c.

Prata, T. A. "A estrutura da autoconsciência na filosofia da mente de John Searle". In: Veritas (PUCRS), Vol. 62, No2, maio-ago., p. 428-452, 2017 a.

Prata, T. A. "Apresentação do artigo 'Uma teoria da consciência' de David Rosenthal" In: Perspectiva filosófica, Vol. 44, $\mathrm{N}^{\mathrm{o}}$ 2, pp. 133-142, $2017 \mathrm{~b}$.

Prata, T. A. "A concepção sartreana da consciência na perspectiva da filosofia analítica da mente”. In: Oliveira, É. A. M. (Org.), Costa M. R. N.(Org.), Benvinda, N. M.. (Org.). Liberdade, lógica e ação: Homenagem ao Prof. Dr. Juan Adolfo Bonaccini. $1^{\text {a }}$ Ed. Recife: Editora UFPE, pp. 455-468, 2017c.

Prata, T. A. "Uma objeção à concepção disposicional dos fenômenos mentais inconscientes" In: Principia (UFSC), Vol. 22, $\mathrm{N}^{\mathrm{O}} 3$, pp. 507-526, 2018a.

Prata, T. A. "A concepção sartriana da consciência na perspectiva de três teorias contemporâneas". Prometeus, N ${ }^{\mathrm{o}}$ 28, pp. 203-222, Setembro-Novembro 2018b.

Prata, T. A. "A consciência (de) Si sartriana na perspectiva da filosofia analítica da mente". In: Alves de Souza, M. J. (Org.); Lima Filho, M. M. (Org.). Escritos de Filosofia II: Linguagem e Cognição. Porto Alegre: Editora Fi, pp. 53-68, 2019.

Rosenthal, D. “Two Concepts of Consciousness”. In: Philosophical Studies, 49, pp. 329-59, 1986.

Rosenthal, D. "A Theory of Consciousness". In: Block, N. (Org.); Flanagan, O. (Org.); Güzeldere, G. (Org.). The Nature of Consciousness: Philosophical Debates. Cambridge (Massachusetts): MIT Press, pp. 729-753, 1997.

Rosenthal, D. "Explaining Consciousness". In: Chalmers, D. (Org.). Phiosophy of Mind: Classical and Contemporary Readings. Oxford: Oxford University Press, pp. 406-21, 2002.

Rosenthal, D. "Higher-Order Theories of Consciousness". In: McLaughlin, B. (Ed.). Beckermann, A. (Ed.). Oxford Handbook of the Philosophy of Mind. Oxford: Oxford University Press, pp. 239-52, 2008 a.

Rosenthal, D. "Consciousness and its Function". In: Neuropsychologia, 46, pp. 829-40, $2008 b$. 
Rosenthal, D. "Uma teoria da consciência". Perspectiva filosófica, Vol. 44, N², pp. 143-78, 2017.

Sartre, J.-P. La transcendece de l'Ego - esquisse d'une description phénoménologique. Paris: Vrin, 1966.

Sartre, J.-P. "A transcendência do ego - esboço de uma descrição fenomenológica" In: Cadernos Espinosanos, XXII, pp. 183-228, 2010.

Searle, J. R. Speech Acts: An Essay in the Philosophy of Language. Cambridge: Cambridge University Press, 1969.

Searle, J. R. Os actos de fala: um ensaio de filosofia da linguagem. Coimbra: Livraria Almedina, 1981.

Searle, J. R. Intentionality: An Essay in the Philosophy of Mind. Cambridge: Cambridge University Press, 1983.

Searle, J. R. Intencionalidade. São Paulo: Martins Fontes, 1995.

Smith, D.W. “The Structure of (Self-)Consciousness”. In: Topoi, 5, pp. 149-56, 1986. 


\title{
Explicando a consciência ${ }^{i}$
}

\author{
David Rosenthal ${ }^{\text {ii }}$ \\ Tradução: Gabriel Dutra ${ }^{\text {iii }}$ \\ Revisão: Tárik de Athayde Prata ${ }^{\text {iv }}$
}

Dentre os fenômenos mentais, nenhum parece resistir tão resolutamente a uma explicação informativa quanto a consciência. Parte da dificuldade se deve ao nosso uso do termo 'consciente' e seus cognatos para dar conta de diversos fenômenos distintos, cujas conexões entre si não são sempre claras. E isso nos leva, muitas vezes, a misturar estes diferentes fenômenos. Qualquer tentativa de explicar a consciência, portanto, deve começar distinguindo as várias coisas que nós chamamos de consciência.

Um destes fenômenos está intimamente relacionado ao simples estar acordado. Nós descrevemos pessoas, e outras criaturas, como estando conscientes quando elas estão despertas e seus sistemas sensoriais estão receptivos, ao modo corriqueiro para um estado desperto. Eu chamo este fenômeno de consciência de criatura [creature consciousness]. Consciência, neste sentido, é um assunto biológico, que consiste em que a criatura não esteja inconsciente - isto quer dizer, mais ou menos, que ela não está adormecida ou desmaiada.

Mas nós também usamos o termo 'consciência' para outros fenômenos que parecem muito menos tratáveis para o entendimento e a explicação. Nós não apenas distinguimos entre criaturas conscientes e inconscientes; nós também distinguimos os estados mentais que são conscientes daqueles que não o são. Eu chamarei esta segunda propriedade de consciência de estado [state consciousness]. É amplamente reconhecido que nem todos os estados mentais são conscientes. Estados intencionais tais como crenças e desejos claramente ocorrem sem que sejam conscientes ${ }^{19}$. E, apesar de alguma divergência de opinião sobre o assunto, eu argumento que o mesmo é verdadeiro para os estados sensoriais, como as dores e as sensações

19 Pace John R. Searle, The Rediscovery of the Mind, Cambridge, Massachusetts: MIT Press, 1992; vide a nota 8, abaixo. Utilizo 'estado intencional' aqui para referir-me a estados, tais como as crenças e os desejos, que exibem conteúdo proposicional ao lado de alguma atitude mental. 
de cor. Tais estados não apenas podem mas, muitas vezes, de fato ocorrem nãoconscientemente ${ }^{20}$.

Embora a consciência de criatura e a consciência de estado sejam propriedades distintas, elas provavelmente se relacionam de diversas maneiras. Talvez, por exemplo, criaturas devam ser, elas mesmas, conscientes para que quaisquer de seus estados mentais sejam conscientes, no entanto, se os sonhos comuns forem estados conscientes, eles serão contraexemplos para esta generalização ${ }^{21}$.

Qualquer que seja o caso com relação a isto, a propriedade da consciência de criatura é relativamente isenta de problemas. Podemos ver isso quando nós consideramos as criaturas menos intelectualmente dotadas do que nós, cujos estados mentais não são conscientes nunca, mesmo quando elas estão $\operatorname{acordadas}^{22}$. Seus estados mentais são todos como os estados mentais não-conscientes que nós temos quando estamos despertos. Sem dúvida que algumas criaturas são realmente assim, como por exemplo, sapos ou tartarugas. E é claro que quando nenhum dos estados mentais de uma criatura é consciente, não há nada enigmático sobre o que é para uma criatura estar consciente. Alguns teóricos podem negar que um tal caso seja possível, enfatizando que nenhuma criatura conta como consciente a não ser que alguns dos estados mentais que ela tenha sejam estados conscientes. Mas isto parece pouco mais do que uma extrapolação infundada do estado de vigília humano normal para o caso de todas as criaturas. Além disso, mesmo se a visão deles estivesse correta seria a consciência de estado que introduziria o aparente mistério.

O que é enigmático sobre a consciência deve ser, portanto, não uma questão de consciência de criatura, mas da consciência dos estados mentais de uma criatura. Como a consciência de criatura envolve a resposta a estímulos sensoriais, se os estados sensoriais fossem todos conscientes, toda criatura consciente estaria, necessariamente, em algum estado consciente. Mas, ainda assim, seria a consciência dos estados, e não da criatura, que pareceria introduzir o mistério.

Por este motivo, vou focar-me, aqui, na consciência de estado. Depois de estabelecer um trabalho preliminar na seção I, na seção II eu desenvolvo uma hipótese sobre como é para

20 Para algumas observações relacionadas acerca de diferentes usos de 'consciência', vide Edmund Husserl, Logical investigations, London: Routledge \& Kegan Paul, 1970, II, pp. 535-536.

21 'Ordinário' é para excluir os assim chamados sonhos hipnogógicos, que ocorrem em um estado semiacordado. Intuições aqui são, de qualquer modo, dificilmente decisivas. Sonhos muito vívidos são estados conscientes? Nós devemos estar conscientes quando nós estamos neles? Já que não é nem um pouco claro o que se deve dizer a respeito de tais questões, é bastante possível que estados conscientes possam ocorrer sem que a criatura esteja ela mesma consciente.

22 É claro que não existe nada como é para uma tal criatura ser consciente - nada como seria para a criatura. Mas isto não significa que não haja nada que ser consciente. 
um estado mental ser consciente. Nesta hipótese, um estado mental é consciente se for acompanhado de um tipo específico de pensamento. Isto é assim tanto se o estado que é consciente for, ele mesmo, um estado intencional quanto se for sensorial. A seção III, então, dá suporte a esta hipótese com um argumento que recorre à habilidade que criaturas como nós têm de reportar não-inferencialmente seus próprios estados conscientes.

As seções IV e V voltam-se para o caso especial dos estados conscientes qualitativos. Eu argumento na seção IV que tal consciência sensorial é apenas um caso especial de consciência de estado que não coloca nenhum problema adicional propriamente seu. E a seção $\mathrm{V}$ traz motivos para pensar que um estado intencional associado pode realmente resultar em que haja um modo como é para alguém ter um estado sensorial consciente. A seção VI, por fim, volta-se para dois questionamentos gerais sobre a consciência de estado: que função ela pode ter e se a consciência pode representar erroneamente quais são os estados em que nós nos encontramos.

\section{Consciência de estado e consciência transitiva.}

Independente de qualquer coisa que nós possamos descobrir sobre a consciência, é claro que se um indivíduo não tem ciência alguma de um estado mental, esse estado não é consciente. Um estado pode, é claro, ser consciente sem que se dê atenção consciente a ele e, na verdade, mesmo que não se tenha consciência sobre cada aspecto mental do estado. Mas se o indivíduo não tem ciência alguma [is not at all aware] de um estado, esse estado não é consciente. Esta observação oferece um ponto de partida útil para uma teoria da consciência de estado. Como não ter ciência alguma de um estado é suficiente para que ele não seja consciente, estar ciente de um estado é, consequentemente, uma condição necessária para que aquele estado seja consciente.

Estar ciente [aware] de um estado mental, entretanto, também não é condição suficiente para que o estado seja consciente. Há maneiras segundo as quais nós podemos ter ciência de nossos estados mentais mesmo quando estes não são estados conscientes. Então, se nós pudermos excluir estas maneiras, irá restar-nos o modo particular de termos ciência de nossos estados mentais quando estes forem estados conscientes. E isto nos daria uma condição tanto necessária quanto suficiente para que um estado mental seja consciente.

De acordo com os propósitos ora presentes, vou falar intercambiavelmente sobre estar ciente [aware] de algo e estar consciente desta coisa. Assim, minha estratégia é explicar a 
consciência de um estado em termos da consciência que nós temos desse estado de uma maneira particular. Não há circularidade no argumento, já que nós estamos explicando um fenômeno nos termos de outro. Uma coisa é termos consciência de algo - o que nós podemos chamar de consciência transitiva [transitive consciousness] - e outra é que um estado seja consciente - o que eu estou chamando de consciência de estado. E nós entendemos a consciência transitiva - a consciência que temos de coisas - independentemente de entender o que é para estados mentais serem estados conscientes. Nós temos consciência transitiva de algo em virtude de estar ou num estado intencional ou sensorial cujo conteúdo é dirigido a esse algo. E a posse que um estado tem de um certo conteúdo é uma propriedade distinta daquela de ser um estado consciente ${ }^{23}$.

Parece ser relativamente incontroverso que um estado do qual alguém não tem nenhum tipo de consciência transitiva não poderia ser um estado consciente. Mesmo o uso de Descartes, que ainda influencia fortemente o nosso, conforma-se a esta observação do senso comum, já que ele descreve invariavelmente os estados que chamamos de conscientes como estados dos quais nós temos consciência imediata. Não obstante, Fred Dretske desfiou recentemente a afirmação de que nós estamos conscientes de todos os nossos estados mentais conscientes. De acordo com Dretske, a consciência de um estado não consiste na consciência que alguém tem do estado; ao invés disso, um estado é consciente se, em virtude de ter este estado, alguém tem consciência de alguma coisa ou de que algo é o caso. Mas todo estado mental satisfaz esta condição; por isso, Dretske precisa afirmar que todos os estados mentais são estados conscientes. De acordo com isto, ele defende que os casos apresentados de estados mentais não-conscientes não são convincentes. Portanto, é comum que se diga que um motorista que dirige longas distâncias e tem um lapso de atenção ainda perceba a estrada inconscientemente ${ }^{24}$, mas Dretske corretamente nota que a percepção pode ser desatenta sem deixar de ser consciente ${ }^{25}$.

23 Mesmo se todas as sensações forem estados conscientes, como é para uma sensação ser [sensação] de alguma coisa seria função não de sua consciência, mas, antes, dos modos como ela assemelha-se e diferencia-se qualitativamente de outras sensações análogas. Falando estritamente, estados mentais não são conscientes de coisas; antes, são criaturas que são conscientes de coisas em virtude de estarem em estados mentais.

24 A melhor versão conhecida do exemplo se deve a D. M. Armstrong, What is Consciousness?, em seu The Nature of Mind, St. Lucia Queensland: University of Queensland Press, 1980: 55-67, p. 59. Vide Naturalizing the Mind, de Dretske, Cambridge, Massachusetts: MIT Press/Bradford Books, 1995, pp. 104105.

25 Conscious Experience, Mind 102, 406 (Abril de 1993): 263-283; reimpresso em Dretske, Perception, Knowledge and Belief: Selected Essays, Cambridge: Cambridge University Press, 2000, 113-37, p. 123; Naturalizing the Mind, cap. 4. 
Entretanto, muitos outros exemplos de estados mentais não-conscientes são bem mais decisivos. Muitas vezes nós nos questionamos conscientemente sobre o que fazer ou como resolver um problema, e a resposta chega a nós apenas num momento posterior, sem que o assunto tenha estado absolutamente conscientemente diante de nossa mente neste meiotempo. Embora não pareça, de um ponto de vista de primeira pessoa, que nós estivéssemos pensando a respeito da questão, é evidente que nós devíamos estar. E diferentemente do caso do motorista de longa distância, neste caso, uma mudança de atenção não mudaria as coisas. Muitas vezes, nós também assimilamos informações sensoriais sem estarmos nem um pouco cientes de fazer isso, e neste caso também, independente de qual seja o foco de nossa atenção. Já que, de um ponto de vista de primeira pessoa, nós não parecemos estar em algum estado sensorial relevante, tais estados não seriam conscientes.

Dretske também argumenta, entretanto, que existem verdadeiros contraexemplos à ideia de que nós estamos transitivamente conscientes de todos os nossos estados conscientes. Para adaptar um pouco seu argumento, considere duas cenas, uma com dez árvores e outra exatamente igual, porém sem uma destas árvores. E suponha que eu veja conscientemente as duas cenas, e que eu vejo, de fato, cada uma das árvores em cada uma delas. Mas suponha, por fim, que a despeito de tudo isso eu não perceba a diferença entre as duas.

Sensivelmente, Dretske assume que neste caso eu tenho experiências conscientes de ambas as cenas, incluindo todas as árvores em cada uma. Ademais, existe alguma parte da experiência consciente de dez árvores que não é parte da experiência consciente de nove árvores. Esta parte é, ela mesma, uma experiência consciente - a experiência consciente de uma árvore. Mas, porque eu não estou transitivamente consciente da diferença entre as duas cenas, Dretske conclui que eu não estarei transitivamente consciente da experiência daquela árvore extra. Se for assim, a experiência da árvore extra é uma experiência consciente da qual eu não estou transitivamente consciente ${ }^{26}$.

Este tipo de coisa dificilmente seria uma ocorrência esotérica. De fato, acontece o tempo todo; permita que uma cena seja sutilmente diferente da outra, de modo que a alteração na segunda cena seja pequena, despercebida. Assim, se o argumento de Dretske for correto, nós comumente falhamos em estarmos conscientes de nossas experiências conscientes ${ }^{27}$.

26 Conscious Experience, pp. 125-128; cf. Naturalizing the Mind, pp. 112-13.

27 Pode-se objetar que nós estamos, em todo caso, conscientes de nossos estados conscientes quando estamos introspectivamente cientes deles. Para precaver-se em relação a esta objeção, Dretske argumentou recentemente que a introspecção assemelha-se ao que ele chama de percepção deslocada [displaced perception]. Assim como nós vimos a saber o quanto o tanque de gasolina está cheio olhando para o gasômetro, nós também vimos a saber qual é o estado mental em que nos encontramos ao notar o quê estamos vendo. É assim que nós nos tornamos conscientes de que estamos em algum estado mental 
Mas o argumento não é correto. Um indivíduo pode estar consciente de uma experiência sob um ponto de vista e não consciente sob outro. Por exemplo, pode-se estar consciente de uma experiência visual enquanto experiência de um borrão opaco, mas não enquanto experiência de um tipo particular de objeto. Similarmente, um indivíduo poderia estar consciente da experiência daquela árvore extra enquanto experiência de uma árvore, ou até mesmo apenas enquanto parte de sua experiência individual mais geral, sem estar de modo algum consciente desta coisa enquanto a coisa que possibilita a diferença entre as duas cenas. Presumivelmente, é exatamente isto que ocorre no exemplo que Dretske constrói. Dretske não descreveu um estado consciente do qual um indivíduo não tem consciência transitiva.

Existe uma complicação na discussão de Dretske que é digna de nota. Dretske insiste que estar consciente de uma diferença, diferentemente de estar consciente de objetos e eventos concretos, sempre resulta em ser consciente "de que tal diferença existe"28. Daí que ele possa afirmar que ser consciente de uma diferença é ser consciente dela enquanto diferença. Mas isto não ajudará. A experiência da árvore extra é aquela em virtude da qual as duas experiências gerais diferem. Ainda assim, um indivíduo pode estar consciente da coisa em virtude da qual elas vêm a diferir sem estar consciente de que elas diferem efetivamente. Como Dretske diria, um indivíduo poderia estar consciente daquilo em virtude de que elas diferem mas não da diferença entre $\operatorname{elas}^{29}$; de fato, ele explicitamente reconhece que exatamente isto pode ocorrer ${ }^{30}$. Portanto, o argumento de Dretske não compromete a observação do senso comum de que nós estamos transitivamente conscientes de todos os nossos estados conscientes ${ }^{31}$.

particular, mas não nos tornamos conscientes do estado (Dretske, Introspection, Proceedings of the Aristotelian Society, CXV 1994/1995, pp. 263-78, e Naturalizing the Mind, cap. 2). Segundo esta proposta engenhosa, a introspecção é uma questão de vir a saber como se pode representar as coisas (pp. 274-75). Mas a introspecção é melhor interpretada enquanto saber em qual estado mental alguém se encontra, independentemente de como este estado representa a realidade não-mental. Mas mesmo se Dretske estiver certo em relação à introspecção, apenas perceber que eu represento as coisas como sendo de um certo modo não me dará a introspecção, a não ser que eu perceba isto conscientemente. Então ou o argumento se apoia nas assunções de Dretske de que todos os estados mentais são conscientes, ou ele precisa oferecer uma explicação diferente do que é para os estados mentais serem conscientes.

28 Conscious Experience, 128; cf. 117-18.

29 No seu útil Dretske on HOT Theories of Consciousness, William Sager faz, independentemente, uma descrição semelhante de como o argumento de Dretske falha em minar a hipótese HOT (Analysis 54, 1 (Janeiro de 1994): 270-76, pp. esp. 275-76).

30 "Mas leitores que só estiveram cientes em relação à diferença entre Alpha e Beta (as duas situações no exemplo de Dretske) como coisa não estiveram conscientes da diferença entre Alpha e Beta enquanto fato" (Conscious experience, p. 128).

31 John R. Searle também nega que nós somos conscientes dos nossos estados mentais conscientes, embora por razões distintas das de Dretske. "No que diz respeito à subjetividade consciente, não há distinção entre observação e coisa observada" (The Rediscovery of Mind, p. 97). O contexto deixa evidente que Searle não está negando apenas que nós possamos observar nossos estados conscientes, mas antes, que nós possamos ter alguma consciência deles segundo a nossa forma de estar consciente de outras coisas: "Nós não podemos 


\section{A hipótese.}

Voltemos, portanto, para a questão sobre o quê há de especial acerca do modo como nós temos consciência transitiva dos nossos estados mentais quando esses estados são conscientes. Talvez o mais óbvio seja que, quando um estado é consciente, nós estamos conscientes dele de um modo que parece imediato. Descartes enfatizou esta imediaticidade intuitiva $^{32}$, que muitos pensaram apontar para uma teoria cartesiana da mente segundo a qual a consciência de um estado mental é uma propriedade intrínseca a ele. Se nada faz a mediação entre um estado e a consciência transitiva que um indivíduo tem dele, talvez esta consciência transitiva fosse algo interno ao próprio estado.

Mas a intuição sobre a imediaticidade não mostra que a consciência de um estado é interna ao estado. Em verdade, a partir de um ponto de vista de primeira pessoa parece que nada realiza a mediação entre os estados conscientes dos quais nós estamos conscientes e a consciência transitiva que nós temos deles. Mas o que isso mostra, apenas, é que se algo realiza uma mediação entre um estado consciente e a nossa consciência transitiva deste estado, o fator mediador não é um do qual nós estamos conscientes. E a ausência de mediação consciente não é motivo para pensar que mediação não-consciente não pode ocorrer ${ }^{33}$. Foi a falha nesta consideração que levou algumas pessoas a defender que nós temos consciência dos nossos estados conscientes de um modo completamente distinto do modo como nós temos consciência de todas as outras coisas.

Mesmo quando algo faz a mediação entre um estado mental consciente e a nossa consciência dele, nós podemos ter consciência do fator mediador; nós apenas não podemos ter consciência dele na medida em que ele opera a mediação. Compare com o que ocorre na

atingir a realidade da consciência no mesmo modo que, usando a própria consciência, nós podemos atingir a realidade de outros fenômenos" (96-97). Isto porque "no que diz respeito à subjetividade consciente, não há distinção entre observação e coisa observada" (97). Searle defende isso apelando à ideia de que nós só podemos descrever a consciência em termos daquilo sobre que ela é consciente (96). Mas mesmo se for assim, haverá estados em virtude dos quais nós somos conscientes de coisas. Então não segue que não existem estados em virtude dos quais nós estamos conscientes dos nossos estados conscientes.

32 “A palavra 'pensamento' aplica-se a tudo o que existe em nós de modo tal que nós estejamos imediatamente conscientes disto" (demonstração geométrica da Second Replies, Oeuvres de Descartes, ed. Charles Adam e Paul Tannery, Paris: J. Vrin, 1964-75, VII, p. 160).

33 Mediação não-consciente, além disto, pode muito bem ocorrer; fatores dos quais nós não estejamos, de modo algum, conscientes muitas vezes operam mediação causal entre diferentes estados mentais, mesmo quando nós estamos cientes deles de um ponto de vista de primeira pessoa. Nosso senso intuitivo de que a consciência que temos de nossos estados conscientes não é mediada pode ser o que leva Searle a alegar que não existe maneira de nós termos consciência dos nossos estados conscientes (vide nota 13). Este senso também distingue este caso do modo como nós temos consciência perceptiva das coisas, no qual nós às vezes temos consciência do medium em operação. 
percepção. Quando nós percebemos as coisas conscientemente, nossos estados sensoriais conscientes medeiam entre as nossas percepções e os objetos que percebemos, e já que tais estados são conscientes, nós temos consciência deles. Ainda assim, nada nestes casos parece intuitivamente fazer a mediação. Isto é assim porque nós não estamos conscientes de nada como aquilo que opera a mediação. E a melhor explicação para isso, por sua vez, é que os estados sensoriais conscientes que operam de fato a mediação não figuram em nenhuma inferência consciente na qual se baseie a nossa percepção. O mesmo se dá com a maneira como nós temos consciência dos nossos estados mentais conscientes. A consciência que temos deles parece não-mediada porque nós temos consciência deles de um modo que não se apoia em inferências conscientes, isto é, em inferências das quais nós estamos conscientes ${ }^{34}$.

Considere um caso. Estou incomodado, mas não tenho ciência disto. Embora meu incômodo não seja consciente, você observa meu comportamento incomodado e me diz que eu estou incomodado. Existem duas maneiras como eu posso reagir. Posso aceitar o que você me diz, e ainda assim não sentir o incômodo conscientemente. Minha crença de que estou incomodado seria resultado de uma inferência consciente baseada na sua observação, e possivelmente também uma inferência consciente advinda de eu vir a perceber o meu próprio comportamento relevante $^{35}$. Mas há outra possibilidade; sua observação pode me fazer ganhar

34 É necessário um pequeno ajuste para isto. Pode-se sustentar uma teoria na qual uma inferência medeia entre a consciência que temos dos nossos estados conscientes e os próprios estados, embora nós só estejamos conscientes da inferência com base em outra inferência que, por sua vez, está baseada na teoria (agradeço a Eric Lormand por levantar esta possibilidade). Nós ainda consideraríamos conscientes os mesmos estados, ainda que a teoria nos torne conscientes das mediações inferenciais. Nós podemos fundamentar isto estipulando que se um estado é consciente, nós temos consciência dele de uma maneira que não requer que nós tenhamos consciência de qualquer inferência que possa ocorrer. A consciência que temos do estado pode apoiar-se em alguma inferência, mas não em nossa consciência dela. Isto também dá conta de uma possibilidade relacionada. Suponha que, normalmente, inferências das quais nós não estamos conscientes medeiam entre a consciência que temos dos estados conscientes e os próprios estados. Mesmo se nós, de algum modo, ganhássemos consciência de algumas destas inferências sem ajuda da teoria, nós consideraríamos os mesmos estados como conscientes. A estipulação ajustada permite isto. Por que nada do que segue depende deste tipo de questionamento, omitirei esta qualificação. Se o modo como nós temos consciência dos nossos estados conscientes fosse baseado, às vezes, na inferência consciente, então nós saberíamos como é que vimos a ter consciência de tais estados. Embora nós tenhamos consciência de nossos estados conscientes, geralmente nós não temos nenhuma ideia, a partir de um ponto de vista de primeira pessoa, de como é que nós nos tornamos conscientes deles. Este desconhecimento ajuda a explicar o ar de mistério que paira ao redor da consciência de estado.

35 A inferência que medeia conscientemente entre os estados mentais e a consciência que um indivíduo tem de tais estados não precisa começar com o estado mental para que o indivíduo tenha consciência dele; normalmente, a inferência consciente começaria, ao contrário, quando se nota o próprio comportamento ou a partir das observações de outros. E porque tais coisas se devem, causalmente, ao estado mental de um indivíduo, uma tal inferência vale como mediadora entre o estado mental e a consciência que se tem deste estado. Não precisamos, independentemente, evitar a dependência da observação. Intuitivamente, ter consciência de um estado mental pode ser imediato mesmo se isto depender de observação, contanto que não se tenha consciência de que isto é assim. E isto será assim caso não haja dependência em nenhuma inferência consciente. P. ex., se um indivíduo observa o próprio passo alegre e assim, sem nenhuma 
consciência do meu incômodo independentemente de qualquer inferência consciente do tipo. Neste caso meu incômodo teria se tornado um estado consciente.

A consciência de um estado envolve um indivíduo que esteja não-inferencialmente consciente deste estado. Será que conseguimos explicar ainda mais a forma como nós temos consciência transitiva dos nossos estados conscientes? Existem duas maneiras gerais de ter consciência transitiva de coisas. Temos consciência de algo quando vemos, ouvimos ou percebemos a coisa de um outro modo. E nós temos consciência de algo quando temos um pensamento sobre a coisa. Qual tipo de consciência transitiva é relevante aqui? Quando nossos estados mentais são conscientes, nós sentimos, de algum modo, estes estados, ou nós temos pensamentos sobre eles?

O modelo perceptual pode parecer convidativo. Quando percebemos as coisas, intuitivamente parece que nós temos consciência direta delas; nada parece mediar entre nossas percepções e os objetos que percebemos ${ }^{36}$. Então talvez o modelo perceptual possa explicar a aparente imediaticidade da maneira como nós temos consciência de nossos estados conscientes. Mas esta vantagem do modelo perceptual não nos ajudará a decidir entre este modelo e o ponto de vista alternativo, de que nós temos consciência dos nossos estados conscientes por termos pensamentos sobre eles. Ainda que nossos pensamentos muitas vezes se apoiem em inferências conscientes envolvendo percepções e outros pensamentos, muitas vezes isso não é o caso.

Entretanto, existe outra consideração que parece favorecer o modelo perceptual. Uma teoria da consciência deve explicar a dimensão qualitativa de nossos estados sensoriais conscientes. E sentir sempre envolve alguma qualidade sensorial. Portanto se nós temos consciência de nossos estados conscientes por senti-los, talvez possamos explicar a dimensão qualitativa da consciência como devida àquela sensação de ordem superior [higher-order sensing]. Uma tal explicação, entretanto e na melhor das hipóteses, apenas adiaria o problema, já que o aspecto qualitativo desta percepção de ordem superior precisaria, ele mesmo, de uma nova explicação.

As considerações favoráveis ao modelo perceptual não apenas falham em se sustentar; há também razões para rejeitar ativamente o modelo. Sensação de ordem superior [Higherorder sensing] deveria exibir qualidades mentais características; que qualidades seriam estas? Uma possibilidade seria que a percepção de ordem superior [higher-order perception] e o

inferência da qual esteja consciente, toma-se por contente, o modo como este indivíduo tem consciência de estar feliz é intuitivamente imediato.

36 Embora nós reconheçamos, ao refletir, que tal mediação ocorre de fato, normalmente nenhuma inferência consciente medeia, e como foi mostrado, é isto que importa para a intuição da imediaticidade. 
estado percebido exibiriam, ambos, a mesma qualidade sensorial. Mas isto não possui motivações teoréticas. Quando percebemos algo, a qualidade do nosso estado perceptual é diferente de qualquer uma das propriedades do objeto que percebemos. Quando vemos um tomate, por exemplo, o vermelho da nossa sensação não é a mesma propriedade que o vermelho do tomate ${ }^{37}$. Assim, não temos nenhuma razão para pensar que qualidades de ordem superior seriam as mesmas que aquelas dos nossos estados de ordem inferior.

Se as qualidades de ordem superior e inferior forem distintas, porém, é um mistério o que tais qualidades de ordem superior poderiam ser. Quais são as qualidades mentais existentes em nossas vidas mentais que não sejam aquelas que caracterizam nossos estados sensoriais de primeira ordem? E se as qualidades de ordem superior não forem as mesmas que as nossas qualidades de primeira ordem, mas também não forem distintas delas, os estados de ordem superior em virtude dos quais nós temos consciência dos nossos estados conscientes não podem ter absolutamente nenhuma qualidade. Mas se tais estados de ordem superior não possuem propriedades qualitativas, eles só podem ser uma espécie de estado intencional de ordem superior $^{38}$.

Portanto devemos rejeitar o modelo perceptual de como nós temos consciência transitiva dos nossos estados conscientes. A única alternativa é que nós temos consciência de nossos estados conscientes em virtude de termos pensamentos sobre eles. Como tais pensamentos são todos sobre outros estados mentais, vou referir-me a eles como pensamentos de ordem superior [higher-order thoughts - HOTs].

Isto restringe um pouco a maneira como nós temos consciência transitiva de nossos estados mentais quando estes estados são conscientes. Mas nós podemos restringir as coisas ainda mais. Quando um estado mental é consciente, nós temos consciência de nos encontrar nesse estado; então o conteúdo do nosso HOT deve ser, mais ou menos, de que um indivíduo

37 Sobre isto, vide David M. Rosenthal, The Colors and Shapes of Visual Experiences, em Consciousness and Intentionality: Models and Modalities of Attribution, ed. Denis Fisette, Dordrecht: Kluwer Academic Publishers, 1998, pp. 137-69; e The Independence of Consciousness and Sensory Quality, em Consciousness: Philosophical Issues, 1, 1991, ed. Enrique Villanueva, Atascadero, California: Ridgeview Publishing Company, 1991, pp. 15-36, reimpresso em Consciousness and Mind, Oxford: Clarendon Press, a ser publicado.

38 Estas considerações são reminiscentes de uma argumentação de Aristóteles contida em De Anima III, 2, 425b12-14, embora Aristóteles também tenha defendido que o vermelho de nossa percepção é exatamente a mesma qualidade que o vermelho dos objetos físicos (p. ex., De Anima, II, 5, 418a4; II, 11, 423b31; II, 12, 424a18; III, 2, 425b23). Talvez as qualidades dos estados de ordem superior sejam aquelas que os nossos estados sensoriais parecem ter, e as qualidades de ordem inferior não figurem no modo como é para nós estar em estados sensoriais. Mas situar no nível superior as qualidades que figuram no modo como é estar em estados sensoriais não ajuda a explicar a dimensão qualitativa desses estados. 
está precisamente neste estado ${ }^{39}$. E já que estar meramente disposto a ter algum pensamento sobre algo não faz um indivíduo ter consciência deste algo, o HOT precisa ser um pensamento ocorrente, ao invés, de ser somente uma disposição a pensar que se está no estado visado [target state]. Além disso, quando temos consciência de uma coisa por estarmos num estado intencional que é sobre esta coisa, o estado intencional é, normalmente, assertórico. De fato, é provável que estar num estado intencional cuja atitude mental não é assertórica não resulte em que o indivíduo tenha consciência da coisa que é conteúdo deste estado intencional ${ }^{40}$. Então nós deveríamos exigir que o HOT tenha uma atitude mental assertórica ${ }^{41}$. Finalmente, para capturar a intuição sobre a imediaticidade, nós vimos que nossos HOTs devem ser independentes de qualquer inferência da qual nós estejamos conscientes. Nossa hipótese, portanto, é que um estado mental é consciente somente no caso de ser acompanhado por um

39 A preocupação de que criaturas não-linguísticas não possam estar em estados intencionais com um tal conteúdo sofisticado pode também motivar a preferência pelo modelo perceptual, já que perceber é um fenômeno mental menos sofisticado. Mas pouca riqueza conceitual é necessária para estar em tais estados intencionais. O conceito de self, p. ex., não precisa envolver mais do que a distinção entre si mesmo e todas as outras coisas. E o estado ele mesmo pode ser conceitualizado de maneira relativamente mínima, digamos, apenas enquanto algum modo como a criatura está.

40 Por isso os HOTs não são apenas sobre conteúdos intencionais, mas sobre estados intencionais plenamente realizados: conteúdos mais atitudes mentais. Se eu duvido ou imagino se um objeto físico particular é vermelho, tenho consciência do objeto; igualmente se eu aguardo, tenho esperança ou desejo que ele seja. Mas não é a dúvida, suposição, esperança ou desejo que me faz consciente do objeto. Antes, se duvido ou desejo ou suspeito que um objeto é vermelho, devo também pensar assertivamente que o objeto está lá, ou existe, e tenho consciência do objeto em virtude de ter esse pensamento assertórico sobre ele. Isto é evidente porque, em tal caso, eu não teria consciência do objeto enquanto vermelho, mas apenas enquanto algo que existe. O conteúdo da minha consciência é determinado não pelo conteúdo do meu estado intencional nãoassertórico, mas pelo estado assertórico. $\mathrm{O}$ mesmo com estados intencionais sobre nossos próprios estados mentais; estar em estados intencionais não-assertóricos sobre os próprios estados mentais só torna o indivíduo consciente de se encontrar em tais estados se eles exigirem que este indivíduo tenha o pensamento assertórico de estar nestes estados. É digno de nota um argumento de Robert M. Gordon de que muitas emoções devem ser acompanhadas por crenças correspondentes; estar com raiva que $p$, por exemplo, exige acreditar que $p$ (The Structure of Emotions: Investigations in Cognitive Philosophy, Cambridge: Cambridge University Press, 1987, pp. 47ff). Se for assim, a crença requerida explicaria por que, quando alguém tem raiva de $p$, ele tem consciência do que quer que $p$ seja a respeito. Em todo caso, este resultado depende de descrever a emoção em termos de seu conteúdo intencional. Portanto, se alguém descreve não que uma pessoa tem raiva de $p$ [angry that $\mathrm{p}$ ], por exemplo, mas que tem raiva por causa de $p$ [angry because $\mathrm{p}$ ], não há uma crença correspondente implicada.

41 Isto ajuda a lidar com uma objeção interessante. Pode parecer que a teoria freudiana postula estados que são não-conscientes a despeito de que eles sejam acompanhados de HOTs apropriados (esta ideia foi defendida por Georges Rey e Stephen Schiffer). Mas não é fácil apresentar exemplos convincentes. Prazer ou culpa sobre estados reprimidos não servem porque prazer e culpa não são assertóricos; então, frequentemente, nós não estamos conscientes dos objetos de nosso prazer ou culpa - mesmo quando tais estados são conscientes. Mesmo que nós conseguíssemos apresentar exemplos plausíveis, ademais, não é nem um pouco óbvio que a teoria freudiana exige que nós descrevamos a situação enquanto envolvendo estados não-conscientes acompanhados de HOTs, já que, normalmente, existem muitas outras explicações igualmente boas para tal fenômeno. Também é importante notar que estados reprimidos raramente são estados não-conscientes. Antes, eles são tipicamente estados que nós escondemos ao representar seus conteúdos de modo radicalmente errado, ou ao distrairmos a nós mesmos criando um ruído mental elaborado. 
pensamento não-inferencial, não-disposicional e assertórico acerca de que o indivíduo está exatamente neste estado ${ }^{42}$.

Um problema que parece ir de encontro a esta hipótese é que, mesmo quando nós estamos em diversos estados conscientes, normalmente nós não estamos cientes de ter tais HOTs. Mas isto não é uma dificuldade; nós só temos consciência dos nossos HOTs quando estes pensamentos forem eles mesmos conscientes, e é raro que eles sejam. Além disso, a hipótese explica prontamente porque isto deve ser assim. Os HOTs que ela postula são pensamentos conscientes somente quando estes forem acompanhados, por sua vez, por pensamentos de uma ordem ainda mais superior que sejam acerca deles, e isto acontece raramente. Não ter HOTs conscientes, ademais, não mostra de maneira nenhuma que nós não temos HOTs que falham em ser conscientes.

Há uma outra razão para que seja útil distinguir os casos em que os HOTs são conscientes dos casos em que não são. A maneira como nós estamos normalmente conscientes dos nossos estados conscientes é diferente da maneira como nós estamos conscientes de estados mentais dos quais nós estamos introspectivamente conscientes. Ter consciência introspectiva de um estado mental envolve, mais ou menos, nossa atenção deliberada focada nesse estado, e apenas alguns poucos dos nossos estados conscientes são objeto de um tal escrutínio introspectivo. Se ter consciência de um estado mental fosse o mesmo que ter consciência introspectiva dele, seria raro termos consciência de nossos estados conscientes, e nós não seríamos capazes de explicar a consciência de estado nos termos da consciência transitiva. Não distinguir as duas, ademais, levaria à concepção errada de que a hipótese dos HOTs serviria apenas como uma teoria da consciência introspectiva, e não da consciência de

42 Segundo Searle, o conteúdo intencional dos estados perceptuais sempre se refere, exatamente, a estes mesmos estados; se vejo um vagão de trem amarelo, o conteúdo da minha percepção visual é "que existe um vagão de trem amarelo aí e que exista aí um vagão de trem amarelo causa a minha experiência visual" (Intentionality: An Essay in the Philosophy of Mind, Cambridge: Cambridge University Press, 1983, p. 48). Se o conteúdo de todo estado perceptual fosse em parte que alguém esteja neste estado, então, na hipótese HOT, apenas ter o estado tornaria o indivíduo consciente dele, e percepções não-conscientes seriam impossíveis (sou grato a Gilbert Haman por expressar esta preocupação). Além disso, é presumível que perceber alguma coisa torna um indivíduo consciente dela, porque, pode-se argumentar, a atitude mental da percepção é assertórica. $\mathrm{O}$ argumento de Searle para esta alegação apela às condições de verdade das percepções; o conteúdo intencional de um estado "determina sob quais condições ele é satisfeito" (p. 48), e só percebemos uma coisa se ela causa uma percepção em nós. Mas as condições sob as quais a percepção é satisfeita são, simplesmente, que existe um vagão de trem amarelo ali, e não, também, que a percepção é causada pela existência de um vagão de trem amarelo ali. A condição causal é relevante não para a verdade do que percebo, mas sim para se eu percebo algo. Entretanto, tais considerações caminham no sentido de uma explicação de quantos estados perceptuais vêm a se tornar conscientes. Nós assumimos, como crença geral sobre o mundo, que os estados de coisas que normalmente percebemos são o que causa os estados perceptuais relevantes. Quando alguém tem o pensamento (tipicamente não-consciente) de que um estado de coisas percebido causou o estado perceptual, este pensamento resulta em um HOT de que o indivíduo está no estado perceptual, e assim, resulta em que o estado seja consciente. 
estado em geral ${ }^{43}$. Mas a presente hipótese, na realidade, permite-nos explicar o que é próprio da consciência introspectiva. Um estado é introspectivamente consciente quando o HOT que o acompanha é um pensamento consciente. Ao contrário disso, a consciência de estado comum, não-introspectiva, ocorre quando o HOT não é ele mesmo consciente.

O modelo HOT é uma hipótese sobre a natureza da consciência de estado, não uma análise desse conceito. Por isso, não vale contra a hipótese que alguém possa, simplesmente, imaginar que ela não é o caso; sempre se pode imaginar as coisas de um modo diferente de como elas realmente são.

Existe um argumento especialmente interessante que apoia a ideia dos HOTs. Quando um estado mental é consciente, o indivíduo pode relatar não-inferencialmente que está nesse estado, ao passo que não poderia relatar seus próprios estados mentais não-conscientes. Além disso, cada ato de fala expressa um estado intencional com o mesmo conteúdo que aquele do ato de fala e uma atitude mental que corresponde a sua força ilocucionária. Daí que um relato não-inferencial de que um indivíduo que se encontra em um estado mental expressará um pensamento não-inferencial de que o indivíduo está nesse estado, ou seja, expressará um HOT sobre o estado. A melhor explicação da habilidade para relatar não-inferencialmente os nossos estados conscientes é supondo que o HOT relevante está lá para ser expresso. Correspondente a isso, a melhor explicação da nossa inabilidade para reportar estados não-conscientes é que nenhum HOT os acompanha ${ }^{44}$.

43 Vide, p. ex., Dretske, Conscious Experience, especialmente a seção 4; também, a resenha de Ned Block sobre o texto de Daniel C. Dennett, Consciousness Explained. The Journal of Philosophy XC, 4 (Abril de 1993): 181-93, que faz alusão, na página 182, à hipótese HOT.

44 Este argumento é desenvolvido em detalhe no meu Thinking That One Thinks, em Consciousness: Psychological and Philosophical Essays, ed. Martin Davies e Glyn W. Humphreys, Oxford: Basil Blackwell, 1993, pp. 197-223. Sobre a conexão entre o pensar e a fala genuína, vide o meu Intentionality, no Midwest Studies in Philosophy, X (1986): 151-84. Ambos serão reimpressos em Consciousness and Mind. O argumento se baseia em criaturas que possam descrever seus estados mentais. Mas reportabilidade nãoinferencial simplesmente ajuda a fixar a extensão de 'estado consciente'; muitas criaturas não-linguísticas também se encontram em estados conscientes. Surgem problemas especiais sobre os estados qualitativos, visto que não é possível expressar verbalmente uma sensação perceptual. Podemos expressar percepções, mas só porque percepções, ao contrário de sensações, tem um aspecto intencional e é este componente intencional que nós podemos expressar verbalmente. Pode ser que o mesmo seja verdadeiro para as sensações corporais; embora nós possamos expressar uma dor murmurando 'ai', não é claro que este 'ai' vale como verbal, em oposição a uma forma não-verbal de expressão. E embora dizer 'estou com dor' seja linguístico, isto relata a dor, e não a expressa. Ainda assim, criaturas com habilidades linguísticas adequadas podem relatar não-inferencialmente seus estados conscientes, sejam eles intencionais ou sensoriais. Tais considerações incidem sobre o modelo perceptual. Quando um estado é consciente, criaturas com a habilidade linguística relevante podem expressar sua consciência transitiva do estado. Se houvesse uma percepção de ordem superior do estado, o relato de um indivíduo expressaria verbalmente apenas o componente intencional daquela percepção de ordem superior. Mas isto é, com efeito, apenas expressar um HOT. Então o argumento baseado no relato e na expressão mostra que se a consciência transitiva de um estado consciente tivesse mesmo um aspecto sensorial, este aspecto sensorial seria irrelevante para que o estado fosse intransitivamente consciente. 
Pode-se contra-argumentar que a habilidade de relatar estados conscientes apenas mostra que há uma disposição para que estes estados sejam acompanhados por HOTs, não que algum HOT efetivamente o acompanha ${ }^{45}$.De fato, Peter Carruthers desenvolveu e defendeu extensamente a concepção de que estados conscientes são apenas aqueles dispostos a serem acompanhados por HOTs, e que nenhum HOT precisaria ocorrer de fato. Isto, argumenta ele, evita ter que postular a capacidade computacional avassaladora e o espaço cognitivo gigantesco que seriam efetivamente necessários para os $\mathrm{HOTs}^{46}$.

Mas esta preocupação não é convincente. Implementação neural não é um problema, já que amplos recursos corticais existem para acomodar os HOTs reais. E embora a introspecção pareça sugerir que a mente não pode realmente acomodar muitos HOTs de uma vez só, esta preocupação também é sem fundamento. A introspecção só pode nos informar sobre nossos estados conscientes, e por hipótese os HOTs só são conscientes raramente.

Em todo caso, o modelo disposicional não pode explicar o que é para os estados serem [estados] conscientes. A consciência de um estado mental consiste em que se tenha consciência deste estado de um modo adequado, e ser simplesmente disposto a ter um pensamento sobre uma coisa não pode tornar um indivíduo consciente dessa coisa. Carruthers enfatiza que nós podemos contornar esta dificuldade se nós entendermos o conteúdo intencional de um estado em termos de quais outros estados intencionais ele é disposto a causar. A disposição de um estado a causar um HOT poderia então conferir um conteúdo de ordem superior adequado a esse estado ele mesmo. Todavia, se a disposição de um estado a causar um HOT fosse função de seu conteúdo intencional, não poderíamos mais explicar como um estado com algum conteúdo particular é às vezes consciente e às vezes não.

\section{Consciência sensorial.}

Segundo este argumento, a consciência sensorial é apenas um caso especial da consciência de estado - o caso especial no qual o estado que é consciente é um estado sensorial. Estados sensoriais são estados com qualidade sensorial. Então a consciência

45 Dennett e Haman, independente um do outro, apresentaram esta réplica em conversação, e ela recebe expressão tácita na posição de Dennett de que "a consciência é a "celebridade' cerebral" (The Message Is: There is no Medium, Philosophy and Phenomenological Research LIII, 4 (Dezembro de 1993): 919-31, p. 929). Vide também Dennett, Consciousness Explained, cap. 10, e pág. esp. 315.

46 Peter Carruthers, Language, Thought and Consciousness: An Essay in Philosophical Psychology, Cambridge: Cambridge University Press, 1996, e Phenomenal Consciousness: A Naturalistic Theory, Cambridge: Cambridge University Press, 2000. 
sensorial ocorre quando um estado mental tem duas propriedades: a qualidade sensorial e a propriedade da consciência de estado.

Além disso, estas duas propriedades são distintas e podem ocorrer independentemente uma da outra. A consciência de estado pode, obviamente, ocorrer sem qualidade sensorial, visto que, muitas vezes, estados intencionais não-sensoriais são conscientes. Mas o contrário também é possível; qualidades sensoriais podem ocorrer sem a consciência de estado. Qualidades sensoriais são, simplesmente, quaisquer propriedades que os estados sensoriais possuem, e a partir das quais nós os distinguimos e organizamos em tipos. Como a consciência de estado consiste na consciência que temos de um estado mental de alguma maneira adequada, tais propriedades são independentes da consciência de estado. Necessitaríamos de alguma razão especial para pensar que as propriedades com base nas quais nós distinguimos entre as sensações não podem ocorrer exceto quando nós temos consciência dos estados que possuem tais propriedades. É difícil conceber que razão especial poderia haver para isto.

Esta conclusão entra em conflito com a afirmação familiar de que a qualidade sensorial não pode ocorrer não-conscientemente. Segundo esta concepção, a consciência de estado é intrínseca, ou essencial, à qualidade sensorial. Mas está longe de ser claro que tal concepção é correta. A percepção subliminar e a visão periférica envolvem, ambas, sensações perceptuais das quais não temos qualquer ciência, e o mesmo é, muito provavelmente, verdadeiro com relação a fenômenos dissociativos como a visão cega ${ }^{47}$. Sensações corporais como dores também podem ocorrer sem serem conscientes. Por exemplo, muitas vezes nós temos uma dor de cabeça ou outra dor durante um período de tempo prolongado, mesmo que distrações nos façam perder qualquer ciência da dor por certos intervalos neste período.

Alguém poderia simplesmente bater o pé e insistir que estes fenômenos são meras ocorrências fisiológicas que não instanciam nenhuma qualidade sensorial, e que, portanto, não são fenômenos mentais de nenhuma maneira. Mas sem uma argumentação independente, esta atitude se mostra apenas como uma tentativa de salvaguardar um posicionamento com um fiat linguístico.

47 Vide Lawrence Weiskrantz, Blindsight, Oxford: Oxford University Press, 1986, e Consciousness Lost and Found: A Neuropsychological Exploration, Oxford: Oxford University Press, 1997. Existem razões para pensar que a discriminação de estímulos com formas diferentes pode ser devida à discriminação de orientação, em lugar da forma ela mesma (Blindsight, p. 84). Van Gulick argumentou que isso mostra que a visão cega não envolve estados com propriedades fenomenais como aquelas de sensações visuais conscientes ("Deficit Studies and the Function of Phenomenal Consciousness", em: Philosophical Psychopathology, ed. George Graham e G. Lynn Stephens, Cambridge, Massachusetts: MIT, 1994.). Mas essa conclusão se segue apenas se assumirmos que as qualidades sensoriais devem ser integradas exatamente do modo que elas são em casos conscientes normais. 
Em todo caso, há boas razões para resistir a esta alegação. Os fenômenos nãoconscientes relevantes ocorrem como partes essenciais de processos notoriamente mentais, e isto sugere que eles próprios são fenômenos mentais ${ }^{48}$. Mais especificamente, estados sensoriais conscientes têm os mesmos papéis no processamento mental quando suas qualidades sensoriais são as mesmas, e, correspondentemente, papéis diferentes quando as qualidades diferem. E os estados não-conscientes da percepção subliminar, visão periférica e da visão cega têm papéis que, ao menos sob alguns aspectos, são análogos aos papéis exercidos pelos estados sensoriais conscientes.

Quando sensações corporais e perceptuais ocorrem conscientemente, nós as classificamos em virtude das qualidades sensoriais de que temos consciência. Em virtude de quê, então, nós classificamos os estados não-conscientes que ocorrem nestes casos? Já que várias das mesmas distinções qualitativas aparecem nos casos não-conscientes e também no sentir consciente, nós devemos assumir que os casos não-conscientes possuem, precisamente, aquelas mesmas propriedades qualitativas ${ }^{49}$. Qualidades sensoriais são as propriedades distintivas dos estados sensoriais, as propriedades em virtude das quais nós classificamos estes estados. Nós usamos as propriedades de que temos consciência para classificar os estados sensoriais em geral, sejam eles conscientes ou não. A única diferença é que nos casos não-conscientes nós não temos consciência de tais propriedades. E como não há nada problemático acerca de tais propriedades distintivas quando os estados que as possuem não são conscientes, não podem haver motivos para achar estas propriedades enigmáticas quando nós temos consciência delas. Qualidades sensoriais parecerão misteriosas somente se nós assumirmos que elas não podem ocorrer sem serem conscientes. Tais considerações fazem com que a afirmação de que qualidade sensorial deve ser consciente soe menos como uma intuição convincente do senso comum e mais como uma doutrina teorética que conclui seu próprio pressuposto [question begging].

É claro que não existe o modo como é ter uma dor ou sensação do vermelho sem que a sensação em questão seja consciente. E daí surgiram argumentos que levaram à conclusão de que uma qualidade sensorial simplesmente não pode existir a não ser que exista o modo como

48 Um exemplo clássico é o assim chamado efeito de festa de coquetel. É comum que nós abafemos os sons de outras conversações que não a nossa, embora a menção do nosso próprio nome em uma das conversas abafadas nos faça mudar repentinamente o nosso foco de atenção para a outra conversa.

49 Compare argumentações análogas de que certos estados não-conscientes têm propriedades mentais devido aos papéis que eles exercem em processos mentais; p. ex., J. A. Fodor, Methodological Solipsism Considered as a Research Strategy in Cognitive Psychology, em The Behavioral and Brain Sciences III, 1 (Março de 1980): 63-73. 
é tê-la ${ }^{50}$. Mas como é para um indivíduo ter uma dor, no sentido relevante desse idioma, é simplesmente como é para ele ter consciência de ter a dor. Portanto, não haverá o modo como é ter a dor a não ser que a dor seja consciente. É claro que se dores não-conscientes fossem impossíveis, não haveria diferença entre a existência de uma dor e que ela fosse consciente, e sua qualidade sensorial só existiria, então, quando houvesse o modo como é tê-la. Mas simplesmente assumir que as dores, ou outras sensações, não podem ocorrer nãoconscientemente, é transpor o pressuposto para a conclusão [it begs the question]. Ademais, a intuição de que estados sensoriais não podem existir não-conscientemente ganha quaisquer forças que ela tenha de nossa perspectiva de primeira pessoa. E não é razoável recorrer à consciência para descobrir se algum fenômeno pode existir fora dela.

Em uma série de artigos produtivos, Ned Block defendeu que há duas propriedades distintas pertencentes aos estados mentais, ambas às quais nós chamamos consciência. Uma é capturada pela noção de que existe uma maneira como é, para um indivíduo, se encontrar em algum estado mental particular; Block chama essa propriedade de consciência fenomenal [phenomenal consciousness]. Um estado possui a outra propriedade quando seu conteúdo é “preparado para ser utilizado como premissa num raciocínio... [e] para [o] controle racional da ação e... da fala" ${ }^{51}$. Esta segunda propriedade é chamada por Block de consciência de acesso [access consciousness]. E ele sustenta que as duas propriedades são, ao menos conceitualmente, independentes. Se Block estiver correto, não existe uma única propriedade da consciência de estado, e o tipo de consciência característico dos estados sensoriais é, ao menos conceitualmente, distinto do tipo exibido por muitos estados não-sensoriais.

A ideia por trás da concepção de Block sobre a consciência de acesso é que a capacidade de um estado de exercer vários papéis executivos, inferenciais e descritivos envolve o acesso do indivíduo àquele estado, que é o acesso a um estado que o torna consciente. Mas este não é sempre o caso. Muitas vezes os estados têm papéis executivos, inferenciais e até alguns papéis descritivos ${ }^{52}$ sem que sejam conscientes em qualquer sentido intuitivo. Então, para que um estado seja consciente por acesso, o indivíduo deve ter acesso ao

50 Vide o What Is It Like to Be a Bat?, de Thomas Nagel, em The Philosophical Review LXXXIII, 4 (Outubro de 1974): 435-50; Panpsychism, em Mortal Questions, Cambridge: Cambridge University Press, 1979, pp. 181-95. e The View From Nowhere, Nova Iorque: Oxford University Press, 1986, caps. 1-4.

51 On a Confusion about a Function of Consciousness, The Behavioral and Brain Sciences, 18, 2 (Junho de 1995): 227-47, p. 231; ênfase de Block. Vide também a resenha de Block ao Consciousness explained, de Dennett, p. 184; Begging the Question Against Phenomenal Consciousness, The Behavioral and Brain Sciences 15, 2 (Junho de 1992): 205-6; Consciousness and Accessibility, The Behavioral and Brain Sciences XIII, 4 (Dezembro de 1990): 596-98.

52 Não é que os estados que nós relatamos sejam não-conscientes, mas estados não-conscientes influenciam o que nós relatamos e como nós fazemos isto. 
estado, presumivelmente, tendo consciência transitiva de uma maneira intuitivamente imediata $^{53}$.

O apelo de Block aos estados que exercem estes papéis é, sem dúvida, reflexo de um desejo de explicar este tipo de consciência em termos funcionais inspirados pela teoria computacional, através de um fluxograma que mapeie as conexões de um estado com os vários sistemas relevantes. Mas para que uma tal tentativa seja bem-sucedida, ela deve ser reflexo de uma explicação inicial de tal consciência em termos da psicologia do senso comum. Ir direto a uma explicação sub-pessoal provavelmente não vai oferecer, nem mesmo, uma explicação extensionalmente adequada.

Sem dúvida Block está correto em que a consciência de acesso, muitas vezes, ocorre sem consciência fenomenal. Nós frequentemente temos acesso aos nossos estados mentais, de modo relevante para o caso, sem que haja o modo como é para nós estar nestes estados. $\mathrm{Na}$ verdade, é assim, tipicamente, que acontece com os nossos pensamentos e outros estados intencionais. Mas o inverso é bem menos evidente. Um estado é consciente por acesso somente se o indivíduo tem consciência transitiva dele. E se um indivíduo não tem, de maneira nenhuma, consciência transitiva de um estado mental, então não existe o modo como é para um indivíduo se encontrar no estado. Não é suficiente que o estado apenas possua as propriedades distintivas características de algum tipo de estado sensorial; para que exista o modo como é ter um estado mental, o indivíduo deve estar consciente de tais propriedades distintivas. Então a consciência fenomenal não pode ocorrer sem a consciência de acesso. A distinção feita por Block não mostra, afinal, que os estados sensoriais são conscientes de maneira distinta de outros tipos de estados mentais, nem que estados sensoriais são, de alguma maneira especial, invariavelmente conscientes ${ }^{54}$.

53 A definição dada por Block da consciência de acesso em termos de um estado estar "preparado" [poised] para determinadas coisas dá um caráter disposicional [dispositional mark] a tal consciência (na resenha ao livro de Dennett ele utiliza a expressão "livremente disponível”, p. 182). Isto é compatível com a ideia de que a consciência de acesso consiste na consciência transitiva que um sujeito possui de um estado mental, em vez de simplesmente estar disposto a ser consciente deste estado. Estados dos quais nós temos consciência transitiva possuem muitas propriedades disposicionais, dentre as quais ser relatável e introspecionável.

54 Block distingue ainda um terceiro conceito de consciência, à qual ele chama consciência reflexiva (resenha a Dennett, p. 182) ou consciência de monitoramento [monitoring consciousness] (On a Confusion, p. 235). De acordo com Block, um estado é consciente dessa maneira se um indivíduo tem um HOT sobre ele. Mas os estados que ele conta como conscientes de modo reflexivo ou do modo de monitoramento são estados dos quais nós temos consciência introspectiva: estados dos quais nós temos consciência de estar conscientes. Esta é uma noção de consciência diferente, mas Block está enganado ao defini-la em termos de possuir HOTs. Antes, um estado possui consciência de monitoramento, nos termos dele, somente se o indivíduo tem um HOT consciente sobre ele. Vide a nota 25. Para mais sobre Block, vide Rosenthal, Phenomenal Consciousness and What It's Like, The Behavioral and Brain Sciences 20, 1 (Março de 1997), pp. 64-65, The Kinds of Consciousness, MS, e How Many Kinds of Consciousness, MS. 


\section{HOTs e "o modo como é".}

Não obstante, parece realmente haver um problema sério sobre o que é para os estados sensoriais serem [estados] conscientes. Quando um estado sensorial é consciente, existe o modo como é para nós estar neste estado. Quando não é consciente, nós não vivenciamos conscientemente nenhuma de suas propriedades qualitativas; então não existe, para nós, o modo como é se encontrar nesse estado. Como podemos explicar esta diferença? Que um estado sensorial seja consciente significa que nós temos consciência transitiva deste estado de alguma maneira adequada. Então ter consciência transitiva de um estado sensorial, dessa maneira particular, deve resultar em um modo como é se encontrar nesse estado. Mas como pode ser que ter consciência transitiva de um estado sensorial leve a este resultado? Que maneira de ser transitivamente consciente dos nossos estados sensoriais poderia, por si mesma, dar ensejo à existência de um modo como é para nós estar nestes estados? Talvez, afinal, Block esteja correto que a consciência de um estado sensorial não seja dependente de um indivíduo ter acesso adequado a ele.

A dificuldade parece particularmente importante para a hipótese HOT. Um dos atrativos do modelo perceptual era que ele poderia ajudar a explicar a dimensão qualitativa dos nossos estados sensoriais conscientes. Visto que perceber envolve qualidades sensoriais, se a consciência de um estado consistisse na percepção que dele temos, talvez pudéssemos explicar a maneira como nós temos consciência das qualidades de nossas sensações conscientes. Como vimos, tal explicação falha, uma vez que as qualidades de ordem superior às quais ela recorre precisariam, elas mesmas, ser explicadas. Mas a hipótese HOT pode parecer ainda menos pertinente para lidar com este problema. Como pode ser que um estado intencional, de qualquer tipo, possuído por um indivíduo resulte na existência do modo como é para este indivíduo estar num estado sensorial?

Há duas maneiras para a teoria HOT tentar mostrar que ter um estado intencional adequado pode ter esse resultado. Uma seria mostrar que é evidente, a partir de um ponto de vista em primeira pessoa, que um indivíduo tem um HOT adequado quando, e somente quando, existe o modo como é para ele ter um estado sensorial. Poderíamos argumentar então que a posse individual deste HOT é responsável pela existência do modo como é se encontrar neste estado. 
Mas se a hipótese HOT estiver correta, não podemos esperar que se encontrarão tais correlações em uma perspectiva de primeira pessoa. Isto porque, segundo a hipótese, os HOTs em virtude dos quais os nossos estados sensoriais são conscientes raramente são pensamentos conscientes. E quando um pensamento não é consciente, parecerá, numa perspectiva de primeira pessoa, que o indivíduo não o tem.

Então, se a hipótese HOT estiver correta, raramente parecerá numa perspectiva de primeira pessoa que os HOTs acompanhem os estados sensoriais conscientes de um indivíduo. Nosso acesso de primeira pessoa só revela correlações com os nossos HOTs conscientes, e não com HOTs em geral. E os HOTs só são conscientes naqueles raros casos em que o indivíduo tem um pensamento de terceira ordem sobre o HOT. Mas na hipótese HOT, HOTs não precisam ser conscientes para que exista o modo como é estar nos estados sensoriais visados. Então não podemos ter a esperança que é possível testar a hipótese estabelecendo, através de uma perspectiva em primeira pessoa, correlações entre a ocorrência de HOTs com a existência do modo como é se encontrar nestes estados sensoriais.

Mas nós não precisamos depender apenas de considerações em primeira pessoa; há outros fatores que ajudam a estabelecer a correlação entre ter HOTs e a existência do modo como é para um indivíduo estar em estados sensoriais conscientes. Em particular, existe uma conexão notável entre quais HOTs nós conseguimos ter e de quais qualidades sensoriais nós podemos ter ciência. E a melhor explicação para tal conexão é que o HOT associado resulta, efetivamente, em que haja o modo como é para um indivíduo ter um estado com tais qualidades sensoriais.

Considere a degustação de vinhos. Aprender novos conceitos para nossas experiências de propriedades gustativas e olfativas apresentadas pelo vinho nos leva, normalmente, a ter consciência de diferenças mais sutis entre as qualidades de nossos estados sensoriais. $\mathrm{O}$ mesmo se dá com outras modalidades sensoriais; adquirir novos conceitos para experiências artísticas e musicais específicas, por exemplo, nos permite ter experiências conscientes com qualidades sensoriais mais finamente diferenciadas. De algum modo, os novos conceitos parecem gerar novas qualidades sensoriais conscientes.

Há duas maneiras como isso pode ocorrer. Uma é que vir a ter novos conceitos resulte em que os nossos estados sensoriais ganhem propriedades distintivas que eles antes não possuíam. Isto é altamente implausível. Como poderia ser que a mera aquisição de novos conceitos fizesse surgir novas propriedades em nossos estados sensoriais? Segundo um ponto de vista muito difundido, conceitos são habilidades para pensar certas coisas; como poderia 
ser que possuir uma nova habilidade mudasse as propriedades de estados sensoriais que resultam do mesmo tipo de estímulo?

Entretanto, há outra possibilidade. Os novos conceitos podem resultar em novas qualidades conscientes não porque geram tais qualidades, mas porque fazem com que nos tornemos conscientes de propriedades que já estavam presentes. Os novos conceitos nos permitiriam ter consciência de qualidades sensoriais que nós já possuíamos, mas das quais não estávamos conscientes ${ }^{55}$.

Possuir um conceito nos permite formar estados intencionais que possuem um determinado alcance de conteúdos. Então quais conteúdos nossos estados intencionais podem ter deve fazer diferença, de alguma maneira, para quais qualidades sensoriais podem ocorrer conscientemente. Além disso, os novos conceitos, que tornam possíveis experiências conscientes com qualidades que parecem novas para nós, são conceitos daquelas mesmas qualidades ${ }^{56}$. Por isso, ser capaz de formar estados intencionais acerca de certas qualidades sensoriais deve resultar, de algum modo, em nossa capacidade de vivenciar conscientemente tais qualidades. Ou seja, deve resultar na existência do modo específico como é para nós estar nos estados sensoriais relevantes.

Como isto poderia acontecer? A única explicação plausível é que a consciência de uma qualidade sensorial consista, efetivamente, na nossa posse de um HOT sobre esta qualidade. Isto é verdadeiro não apenas para as qualidades relativamente bem diferenciadas que nós estivemos considerando quase agora. Podemos extrapolar, para qualquer qualidade sensorial, não importa o quão cruamente individuada, e extrapolar até mesmo para se nós temos ou não consciência de alguma qualidade.

Tomemos como exemplo a experiência consciente de ouvir o som de um oboé. Se o HOT de um indivíduo não pudesse classificar as sensações dele em termos do som de um oboé, mas somente como som de uma madeira qualquer, indiferenciada, ter a sensação não poderia ser, para o indivíduo, como ouvir um oboé. E se também lhe faltasse qualquer

55 Evidentemente que, muitas vezes, os estados sensoriais relevantes aqui terão sido conscientes antes de o indivíduo adquirir os conceitos mais refinados, mas conscientes somente com respeito a qualidades individuadas de maneira mais grosseira. P. ex., um indivíduo pode estar, inicialmente, consciente um tipo particular de sensação olfativa apenas como típica do vinho, e subsequentemente tornar-se consciente dela em termos de qualidades sensoriais refinadas.

56 Pode-se argumentar que os novos conceitos são pertinentes não às propriedades distintivas de nossas experiências sensoriais conscientes, mas antes, às propriedades perceptíveis dos objetos e processos físicos percebidos, p. ex., o vinho ou a performance musical (vide Haman, The Intrinsic Quality of Experience, Philosophical Perspectives, 4: Action Theory and Philosophy of Mind, 1990, pp. 31-52). Mas é claro que nos casos há pouco imaginados nós também focamos introspectivamente nas propriedades distintivas de nossos estados sensoriais conscientes. Então estes casos envolvem novos conceitos das propriedades distintivas de estados sensoriais. 
conceito em geral do que é o som de uma madeira ${ }^{\mathrm{v}}$, o modo como seria para o indivíduo ter esta sensação seria respectivamente algo ainda mais genérico. Se ao indivíduo faltasse mesmo o conceito do que é uma sensação sonora em contraposição a outro tipo de estímulo, ter a sensação seria, para ele, como ter uma experiência sensorial indiscriminada qualquer. Esta sequência torna plausível que a remoção daquele último HOT mais fraco e superficial acabaria por fazer com que não existisse mais sequer o modo como é ter aquela sensação em absoluto. Ainda que os HOTs sejam apenas estados intencionais, e então não possuam propriedades qualitativas, ter HOTs é faz efetivamente diferença quanto a se existe ou não o modo como é para um indivíduo ter sensações particulares.

Porque os HOTs raramente são conscientes, não podemos, de um ponto de vista de primeira pessoa, notar a ocorrência de HOTs quando, e somente quando, nos encontramos em estados sensoriais conscientes. Ainda assim, o argumento da degustação de vinhos se baseia, de fato, em considerações de primeira pessoa. Nós sabemos, num modo de primeira pessoa, que aprender novos conceitos para qualidades sensoriais é suficiente para que nos tornemos conscientes de nossos estados sensoriais enquanto detentores de tais qualidades. E com base nisto, podemos inferir que HOTs não-conscientes são responsáveis pela existência de um modo como é para um indivíduo ter consciência dos estados sensoriais dessa maneira. O caso é simplesmente que a correlação direta entre HOTs não-conscientes e estados sensoriais conscientes não está disponível numa perspectiva de primeira pessoa.

Inferir correlações a partir de considerações de uma perspectiva em primeira pessoa é suficiente? Ou deveríamos mesmo trabalhar completamente dentro de uma perspectiva em primeira pessoa, se nosso objetivo for mostrar que os HOTs são responsáveis pela existência de um modo como é para um indivíduo ter estados sensoriais conscientes?

Uma teoria da consciência deve explicar os aspectos de primeira pessoa dos nossos estados conscientes. Mas a explicação não necessita, ela mesma, depender somente de aspectos de primeira pessoa. Com efeito, exigir outra coisa é tornar uma tal explicação viciosamente circular. Então o fator responsável pela existência de um modo como é ter um estado sensorial não precisa ser, ele mesmo, um aspecto de primeira pessoa deste estado, nem mesmo algo disponível a partir de uma perspectiva de primeira pessoa. Os HOTs em virtude dos quais nossos estados mentais são conscientes não precisam, eles mesmos, serem pensamentos conscientes.

Compare as relações causais que os estados sensoriais conscientes possuem com estímulos, comportamentos e outros estados mentais. Estas relações são tipicamente 
indisponíveis a partir de um ponto de vista de primeira pessoa; nós devemos inferi-las de outras considerações, tanto de primeira quanto de terceira pessoa. De modo semelhante, podemos esperar que, qualquer que seja a coisa responsável pela existência de um modo como é para um indivíduo ter estados sensoriais conscientes, ela não será diretamente acessível a partir de um ponto de vista de primeira pessoa, mas deve, ao invés disso, ser conhecida por via de inferência teórica.

Alguns teóricos insistiram que nenhuma correlação ou desenvolvimento teórico poderia nos permitir entender completamente como ocorrências fisiológicas fazem surgir um modo como é para um indivíduo ter estados conscientes qualitativos. Se isto for correto, talvez, nós também não possamos entender completamente como os HOTs poderiam fazer as qualidades conscientes surgirem.

Joseph Levine chama esta dificuldade de "lacuna explanatória" e argumenta que ela resulta da nossa capacidade de conceber ocorrências fisiológicas sem qualidades conscientes. Por contraste, ele alega, é inconcebível que a água pudesse ferver a uma temperatura diferente, ao menos se o resto da química permanecer o mesmo ${ }^{57}$. Mas nossa habilidade de entender coisas e os limites aparentes ao que nós podemos conceber são sempre relativos às teorias prevalentes, sejam elas científicas ou populares, como a manutenção da permanência da química no argumento de Levine ilustra.

Visto que a aparição de uma lacuna explanatória simplesmente atesta a ausência atual de uma teoria adequada e bem desenvolvida, avanços teóricos concernentes aos estados qualitativos conscientes devem estreitar substancialmente qualquer lacuna que pareça existir agora. E ainda que nunca possamos eliminar a lacuna completamente, é raro que tenhamos um entendimento completo de como um fenômeno macroscópico do senso comum surge, se é que nós temos isso ${ }^{58}$.

O modelo HOT procede independentemente da fisiologia, mas uma lacuna explanatória semelhante parece surgir, já que nós precisamos entender como HOTs não-

57 On Leaving Out What It's Like, em Consciousness: Psychological and Philosophical Essays, ed. Martin Davies e Glyn W. Humphreys, Oxford: Basil Blackwell, 1993, 121-36, p. 134, e Purple Haze: The Puzzle of Consciousness, Nova Iorque: Oxford University Press, 2001, pp. 79. Vide também Materialism and Qualia: The Explanatory Gap, em Pacific Philosophical Quarterly, LXIV, 4 (Outubro de 1983): 354-61. Para argumentos relacionados, vide David J. Chalmers, The Conscious Mind: In Search of a Fundamental Theory, Nova Iorque: Oxford University Press, 1996. De modo semelhante, Nagel alega que nós temos um entendimento puramente racional de porque "calor causa a fervura da água, pedras causam a quebra do vidro, magnetos induzem a corrente elétrica, e o vento provoca [makes] ondas" (Panpsychism, p. 186), mas atualmente carecemos de qualquer entendimento sobre como calor físico, por exemplo, ou um processo cerebral, poderia causar necessariamente [causally necessitate] uma dor ou outra sensação (Panpsychism, p. 187).

58 Vide o meu Reductionism and Knowledge, em How Many Questions?, ed. Leigh S. Cauman, Isaac Levi, Charles Parsons e Robert Schwartz, Indianápolis: Hackett Publishing Co., 1983, 276-300. 
conscientes podem resultar em qualidades conscientes. Conexões causais são irrelevantes aqui, visto que não há necessidade de laço causal entre um HOT e o que ele visa. Antes, os HOTs resultam em qualidades conscientes porque eles nos tornam conscientes de nós mesmos enquanto estamos em certos estados qualitativos, o que resulta na impressão subjetiva de qualidades mentais conscientes. E as considerações levantadas anteriormente nesta seção fornecem razões para sustentar que HOTs podem fazer isto efetivamente.

\section{Consciência, confabulação e função.}

Como finalização, volto-me brevemente para duas implicações inesperadas da hipótese HOT, na verdade, de qualquer teoria em que a consciência de um estado mental consista, como eu argumentei que deve ser, na consciência transitiva que um indivíduo tem do estado.

Como vimos, os HOTs em virtude dos quais os estados mentais são conscientes representam estes estados de maneiras mais ou menos refinadas. E a maneira como nossos HOTs representam os estados que são seus objetos influenciam como estes estados se mostram para nós de um ponto de vista de primeira pessoa. Como é para mim ter uma sensação gustativa particular do vinho depende do quanto de detalhamento e diferenciação estão contidos no HOT em virtude do qual a sensação é consciente. Dado qualquer estado sensorial particular, HOTs diferentes produziriam diferentes modos como é para um indivíduo se encontrar neste estado.

Já que o HOT que acompanha qualquer estado sensorial particular pode ser mais ou menos refinado, não é só o estado sensorial que determina qual HOT o indivíduo terá. Isto também dependerá de fatores adicionais, tais como a extensão do repertório conceitual do indivíduo, seus interesses atuais, o quão atento ele é, e também o quão experiente em fazer as discriminações sensoriais relevantes para o caso.

Isto levanta uma questão interessante. Já que a própria sensação não determina o HOT que o indivíduo tem, por que o HOT não poderia representar incorretamente o estado sensorial em que o indivíduo está? Por que o indivíduo não poderia ter um estado sensorial de um tipo, mas ter um HOT que o representa como tendo um estado sensorial de tipo diferente? Além disso, o HOT que o indivíduo tem determina como é para ele se encontrar no estado sensorial relevante. Então, porque um HOT errôneo não criaria a aparência, de um ponto de 
vista de primeira pessoa, de que o indivíduo tem um estado sensorial no qual ele não está realmente?

Existem razões para acreditar que isto acontece de fato. Pacientes odontológicos às vezes parecem sentir dor, de um ponto de vista de primeira pessoa, mesmo que seja indiscutível que tal dor seja inexistente em decorrência de anestésicos ou de danos ao nervo. A hipótese usual é que o paciente vivencia medo ou ansiedade junto com a vibração da broca, e reage conscientemente como se tivesse dor. Explicar isto ao paciente resulta, em geral, numa mudança correspondente no modo como é para o paciente quando a perfuração prossegue, mas a sensação do paciente a respeito de como foi experiência precedente permanece geralmente inalterada. A aparição prévia de dor não-verídica, é subjetivamente indistinguível da experiência real de dor.

Outros exemplos notáveis ocorrem em conexão com nossas sensações perceptuais. Como salienta Daniel Dennett em Consciousness Explained, a visão parafoveal [parafoveal vision] ${ }^{\mathrm{vi}}$ só pode produzir sensações de baixa resolução da maioria das Marilyns na famosa pintura de Warhol ${ }^{59}$, mas nós estamos cientes de todas elas como claras e focadas. O modo como algo é para nós é uma função não do caráter de nossas sensações, mas de como nós temos consciência destas sensações.

As pessoas também têm uma tendência bem conhecida para confabular que estão em diversos estados intencionais, frequentemente de maneiras que parecem explicar ex post facto o sentido de seu comportamento ${ }^{60}$; aqui, é óbvio que os HOTs representam erroneamente os estados em que os sujeitos se encontram. De modo semelhante, é muito provável que crenças e desejos reprimidos sejam frequentemente, na verdade, crenças e desejos conscientes cujo conteúdo o indivíduo representa de maneira radicalmente errada. Assim alguém pode vivenciar o desejo por uma coisa inaceitável como o desejo por uma outra coisa. Em tal caso, o desejo não é literalmente inconsciente; é um desejo consciente cujo caráter é distorcido por HOTs imprecisos. O modo como é para um indivíduo ter este desejo falha precisamente em representar seu conteúdo real ${ }^{61}$.

59 Daniel C. Dennett, Consciousness Explained, Boston: Little, Brown and Co., 1991, p. 354. Vide pp. 53-54 para a notável ilustração de Dennett de tais limites na tentativa de discernir a cor de cartas de baralho vistas parafovealmente à distância de um braço.

60 Para um estudo clássico, vide Richard E. Nisbett e Timothy DeCamp Wilson, Telling More Than We Can Know: Verbal Reports on Mental Processes, Psychological Review LXXXIV, 3 (Maio de 1977): 231-59. O influente estudo de Nisbett e Wilson não deu atenção apenas aos casos em que os sujeitos confabularam histórias sobre as causas de eles estarem em estados cognitivos particulares, mas também aos casos em que eles confabularam descrições sobre em quais eles estão realmente.

61 Talvez estes HOTs errôneos também possam figurar no auto-engano aparente. Pode parecer difícil, às vezes, dizer se um HOT representa incorretamente um estado efetivamente visado, ou se ele tem apenas uma noção 
A hipótese HOT não é a única teoria a dar espaço para tais coisas; qualquer teoria na qual a consciência de um estado mental consista na consciência transitiva que o indivíduo tem do estado também dará esse espaço. Contanto que um estado consciente seja distinto da consciência transitiva que o indivíduo tem dele, o conteúdo desta consciência transitiva pode representar o estado erroneamente. Estados conscientes são estados dos quais nós estamos conscientes de nos encontrar, independente de se nós nos encontramos realmente neles ou não.

A ideia de que o modo como é para um indivíduo estar em um estado é determinada não pelas propriedades intrínsecas do estado, mas pelo modo como o HOT de um indivíduo o representa, permite-nos entender certos casos que pareceriam intratáveis à explicação de outra maneira. Suponha que você está andando por entre as árvores, pisando sobre galhos à medida que isto for necessário, mas tão fortemente envolvido numa conversação que não presta atenção alguma aos galhos. De um ponto de vista de primeira pessoa, você não parece ter quaisquer pensamentos sobre os galhos; quaisquer pensamentos sobre eles que você tenha não são pensamentos conscientes.

Para atravessar os galhos, entretanto, você presumivelmente necessita mais do que apenas pensamentos sobre eles; você também deve ter sensações dos galhos. Mas de um ponto de vista de primeira pessoa, também pode muito bem parecer que você não tem estas sensações. Mas ao contrário de seus pensamentos, há razões para duvidar que as suas sensações dos galhos falham literalmente em serem conscientes. Não é que inexistam sensações conscientes onde esperar-se-ia sensações de galhos ocorrendo no campo visual de um indivíduo; o campo visual não parece ter lacunas onde as sensações relevantes estariam. $\mathrm{Na}$ verdade, as sensações que a você parecem estar presentes são, mais ou menos, somente sensações indiferenciadas do ambiente campestre.

Por quê, então, você não está ciente das suas sensações dos galhos? Obviamente você tem tais sensações; é assim que você administra seu percurso através dos galhos. E as sensações que você tem da parte relevante do ambiente são todas conscientes; é por isto que seu campo visual não parece conter lacunas. Então deve ser que as sensações são conscientes não como sensações de galhos, mas apenas como sensações do ambiente indiscriminado. Podemos explicar este tipo de ocorrência somente se a maneira nós temos consciência transitiva de nossas sensações determina como é para nós tê-las. Compare o exemplo vívido de Dennett de olhar diretamente para um dedal e falhar em vê-lo como um dedal. É claro que 
a sensação do dedal é consciente, mas o indivíduo não tem consciência dela como a sensação de um dedal e sim, digamos, como sensação de parte da bagunça de uma estante ${ }^{62}$.

Nos casos do dedal e dos galhos, o modo como é para o indivíduo ter estados sensoriais particulares é menos rico informacionalmente do que os estados eles mesmos. Mas o oposto também acontece, como quando nós vivenciamos nossas sensações em baixa resolução das Marilyns parafoveais como se elas fossem claras e focadas. A melhor explicação é que nossos HOTs sobre nossas sensações parafoveais borradas representam-nas como tendo alta resolução; a maneira como nós temos consciência de nossas sensações na verdade as corrige por colocá-las em foco e retocá-las, digamos assim ${ }^{63}$. De fato, isto traz para nós a necessidade de postular estados ocorrentes de ordem superior, visto que a informação de alta resolução deve ser incorporada em um estado ocorrente.

Tal disparidade entre as propriedades de nossas sensações e a maneira como nós temos consciência delas tem implicações importantes. Por exemplo, considere o argumento bem conhecido de Wilfried Sellars de que qualidades sensoriais de sensações exibem uma "homogeneidade fundamental" que as separam do caráter fracionado de propriedades físicas comuns $^{64}$. Sellars defende que esta homogeneidade fundamental deriva da maneira como nós

62 Consciousness Explained, p. 336. De modo semelhante, no efeito de festa de coquetel a atenção do indivíduo muda para uma conversação previamente relegada na qual o nome do indivíduo é mencionado. Então o indivíduo devia estar escutando as palavras articuladas naquela conversa, ainda que ela parecesse à consciência apenas um ruído de fundo. Achados experimentais robustos, p. ex., aqueles envolvendo a préativação mascarada [masked priming], também oferecem evidências convincentes de que o modo como é ter uma sensação às vezes diverge das propriedades da sensação ela mesma. No pré-ativação mascarada, sujeitos relatam não estarem cientes do input qualitativo cuja presença é evidente considerando-se seu efeito sobre o comportamento cognitivo subsequente. Para um estudo clássico, vide Anthony J. Marcel, Conscious and Unconscious Peception: Experiments on Visual Masking and Word Recognition, Cognitive Psychology 15 (1983): 197-237. Trabalhos experimentais com cegueira em relação a mudanças [change blindness] também fornecem evidência vívida de divergência entre o modo como nós temos consciência de nossas sensações e suas propriedades efetivas. Aqui os sujeitos falham em registrar conscientemente mudanças visíveis tão salientes que é esmagadoramente provável que as mudanças correspondentes ocorram em suas sensações visuais. Assim as sensações dos sujeitos divergem da maneira como eles estão cientes delas. Além disso, a impressão convincente que todos nós temos de estar continuamente conscientes de detalhes qualitativos salientes é obviamente incorreta. Vide John Grimes, On The Failure to Detect Changes in Scenes Across Saccades, em Perception, ed. Kathleen Atkins, Nova Iorque: Oxford University Press, 1996, pp. 89-110; Daniel J. Simons, Current Approaches to Change Blindness, em Visual Cognition 7, (2000): 116; e Ronald A. Rensink, The Dynamic Representation of Scenes, Visual Cognition 7, 1/2/3 (Janeiro de 2000): 17-42, e Seeing, Sensing and Scrutinizing, em Vision Research, 40, 10-12 (2000): 1469-87.

$63 \mathrm{Na}$ experiência estética, também, o modo como nós temos consciência de uma sensação presumivelmente excede seu caráter qualitativo. Para mais sobre divergências entre sensações e o modo como nós temos consciência delas, e sobre o modo como os HOTs funcionam neste tipo de conexão, vide Sensory Qualities, Consciousness and Perception - a ser publicado em Consciousness and Mind, e Consciousness and Metacognition, em Metarepresentation: Proceedings of the Tenth Vancouver Cognitive Science Conference, ed. Daniel Sperber, Nova Iorque: Oxford University Press, 2000, 265-95.

64 Frequentemente citado como o "argumento do grão" de Sellars. Wilfrid Sellars, Philosophy and the Scientific Image of Man, em Frontiers of Science and Philosophy, ed. Robert G. Colodny, Pittsburgh: University of Pittsburgh Press, 1962, pp. 35-78; reimpresso em Science, Perception and Reality, 1-40, p. 36; também p. 35, e Phenomenalism, também em Science, Perception and Reality, 60-105, pp. 103-5. 
concebemos, em termos do senso comum, as propriedades perceptíveis dos objetos físicos. Qualquer que seja o caso com relação a isto, é provável que tais qualidades sensoriais das sensações sejam elas mesmas fracionadas. Sendo situada em neurônios, a informação sensorial relevante ocorrerá na forma de pixels particulares que representam cor, forma, movimento e coisas do tipo. Nós vivenciamos tais informações, entretanto, como fundamentalmente homogêneas simplesmente porque é assim que nós temos consciência dos estados informacionais relevantes. A maneira como nós temos consciência de nossas sensações as suaviza para fora, por dizer assim, e elide os detalhes de sua natureza fracionada de bit-map.

Dretske ressaltou que teorias nas quais a consciência de um estado consista na consciência transitiva que um indivíduo tem do estado parecem incapazes de explicar como a consciência de um estado mental poderia ter qualquer função ${ }^{65}$. Ter consciência transitiva do estado, em tais teorias, não faz diferença para as propriedades não-relacionais do estado. Então a consciência do estado não fará diferença em seu papel causal nem, portanto, em sua função.

É fácil superestimar o grau em que a consciência de um estado exerce efetivamente algum papel. É convidativo pensar, por exemplo, que a consciência de um estado melhora, de algum modo, um planejamento ou raciocínio em que o estado apareça. Mas o papel que um estado cumpre no planejamento e no raciocínio se deve ao conteúdo dele, e o conteúdo será invariante seja o estado consciente ou não. Então que um estado seja ou não consciente não afetará o papel do estado no planejamento ou no raciocínio. Nós achamos tentador insistir que a consciência de um estado afeta o planejamento e o raciocínio quando consideramos casos efetivos em que o planejamento e o raciocínio são conscientes. Mas estes casos não nos dizem nada a não ser que nós os comparemos com os casos não-conscientes, aos quais nós não temos um acesso de primeira pessoa. Intuições não podem ajudar aqui.

Em todo caso, Dretske descreveu incorretamente a situação. Segundo a hipótese HOT, um estado consciente é um estado composto, consistindo do estado de que o indivíduo tem consciência mais um HOT. Então o papel causal que um estado consciente cumpre é na verdade a interação de dois papéis causais: aquele exercido pelo estado ele mesmo e aquele exercido pelo $\mathrm{HOT}^{66}$. Isto explica como a consciência de um estado pode importar, até certo ponto, em relação a seu papel causal. Além disso, o modo como um indivíduo tem

65 Naturalizing the Mind, p. 117.

66 A interação entre os dois papéis pode não ser somatória; as propriedades causais do HOT podem interagir com aquelas do estado de modo tal que as propriedades causais originais do estado se modifiquem, ou mesmo que sejam completamente bloqueadas. 
consciência de um estado consciente pode não combinar completamente com o estado visado [pelo HOT] em que o indivíduo realmente se encontra. Em tais casos, o papel causal exercido pelo HOT importará ainda mais. A consciência de estado, afinal de contas, realmente faz alguma pequena diferença em relação às funções que os estados mentais têm ${ }^{67}$.

Mas então o que é que ocorre no caso da intuição convincente de que a consciência de um estado mental faz uma diferença grande e significativa em seu funcionamento mental? Tal intuição é muito provavelmente devida à impressão [sense] que temos de que nossos pensamentos, desejos e intenções conscientes ocorrem livremente e que esta aparente liberdade melhora nossa habilidade de raciocinar e fazer escolhas racionais. Mas pode-se argumentar que a nossa impressão de que estes estados ocorrem livremente, ela mesma, é resultado do modo como nós temos consciência destes estados. Porque nós raramente, ou praticamente nunca, temos consciência da causa de nossos pensamentos e desejos conscientes, nós temos a impressão subjetiva de que eles não são causados, e, portanto, livres. Assim, parece que apenas ter consciência destes estados faz uma diferença significativa no papel que eles desempenham em nossas vidas. É porque o modo como temos consciência de nossos estados intencionais apresenta-os como livres e não-causados que a consciência deles parece importar para nossa habilidade de raciocinar e fazer escolhas racionais.

Argumentei que a hipótese HOT explica como os estados conscientes diferem de estados mentais não-conscientes, e por quê a consciência de estado tem uma função na medida em que tem. Ademais, a hipótese adequa-se bem com a existência do modo como é se encontrar em estados sensoriais conscientes. Nós podemos provisoriamente concluir que a hipótese lida satisfatoriamente com o fenômeno da consciência de estado, mesmo no caso especial dos estados sensoriais.

i Artigo publicado, pela primeira vez, em Chalmers, D. (Org.). Philosophy of Mind: Classical and Contemporary Readings. Nova Iorque; Oxford: Oxford University Press, pp. 406-21, 2002.

ii PhD pela Princeton University (EUA). Professor da City University of New York.

iii Graduado em Filosofia pela Universidade Federal de Pernambuco (UFPE).

iv Doutor em Filosofia pela Ruprecht-Karl Universität Heidelberg (Alemanha). Professor associado do Departamento de Filosofia da Universidade Federal de Pernambuco (UFPE).

v Uma madeira é um instrumento de som que pertence à família musical das madeiras, instrumentos de sopro. Recebem este nome porque, antigamente, todos estes instrumentos eram feitos de madeira, porém hoje muitas madeiras não são mais feitas com o material madeira; por exemplo, o saxofone e o clarinete. Ou seja, se o indivíduo não soubesse que o instrumento pertence à família musical das madeiras, ele poderia achar que se tratasse de algum instrumento musical qualquer. (nota do tradutor).

67 Então o inessencialismo consciente [conscious inessentialism], segundo o qual cada atividade inteligente que nós realizamos conscientemente poderia ser realizada sem que fosse consciente, é errado. O rótulo se deve a Owen Flanagan, que rejeita a tese (Consciousness Reconsidered, Cambridge, Massachusetts: MIT Press/Bradford Books, 1992, pp. 5, 129ff). 
PROMETHEUS - N. 35 - January-April 2021 - E-ISSN: 2176-5960

vi A visão "parafoveal" se baseia em imagens produzidas na área da retina que fica ao redor da fóvea, no interior do globo ocular (nota do revisor). 